Technical Note

\title{
Optimization of Topdressing for Winter Wheat by Accurate Growth Monitoring and Improved Production Estimation
}

\author{
Jingchun Ji ${ }^{1,2} \mathbb{D}$, Jianli Liu ${ }^{1}$, Jingjing Chen ${ }^{3} \mathbb{D}$, Yujie Niu ${ }^{1,2}$, Kefan Xuan ${ }^{1,2}$, Yifei Jiang ${ }^{1,2}$, Renhao Jia ${ }^{1,2}$, \\ Can Wang ${ }^{1,2}$ and Xiaopeng $\mathrm{Li}^{1, *(D)}$ \\ 1 Institute of Soil Science, Chinese Academy of Sciences, Nanjing 210008, China; jcji@issas.ac.cn (J.J.) \\ jlliu@issas.ac.cn (J.L.); niuyujie@issas.ac.cn (Y.N.); kfxuan@issas.ac.cn (K.X.); jyf@issas.ac.cn (Y.J.); \\ jiarenhao@issas.ac.cn (R.J.); wangcan@issas.ac.cn (C.W.) \\ 2 University of the Chinese Academy of Sciences, Beijing 100049, China \\ 3 School of Plant and Environmental Sciences, Virginia Tech University, Blacksburg, VA 24061, USA; \\ jingji9@vt.edu \\ * Correspondence: lixp@issas.ac.cn
}

check for updates

Citation: Ji, J.; Liu, J.; Chen, J.; Niu, Y.; Xuan, K.; Jiang, Y.; Jia, R.; Wang, C.; Li, X. Optimization of Topdressing for Winter Wheat by Accurate Growth Monitoring and Improved Production Estimation. Remote Sens 2021, 13, 2349. https://doi.org/ $10.3390 / \mathrm{rs} 13122349$

Academic Editors: Bin Chen, Yufang Jin and Le Yu

Received: 6 May 2021

Accepted: 12 June 2021

Published: 16 June 2021

Publisher's Note: MDPI stays neutral with regard to jurisdictional claims in published maps and institutional affiliations.

Copyright: (c) 2021 by the authors. Licensee MDPI, Basel, Switzerland. This article is an open access article distributed under the terms and conditions of the Creative Commons Attribution (CC BY) license (https:// creativecommons.org/licenses/by/ $4.0 /)$.

\begin{abstract}
Topdressing accounts for approximately $40 \%$ of the total nitrogen $(\mathrm{N})$ application of winter wheat on the Huang-Huai-Hai Plain in China. However, $\mathrm{N}$ use efficiency of topdressing is low due to the inadaptable topdressing method used by local farmers. To improve the $\mathrm{N}$ use efficiency of winter wheat, an optimization method for topdressing $\left(\mathrm{T}_{\mathrm{HP}}\right)$ is proposed that uses unmanned aerial vehicle (UAV)-based remote sensing to accurately acquire the growth status and an improved model for growth potential estimation and optimization of $\mathrm{N}$ fertilizer amount for topdressing (NFT). The method was validated and compared with three other methods by a field experiment: the conventional local farmer's method $\left(\mathrm{T}_{\mathrm{LF}}\right)$, a nitrogen fertilization optimization algorithm (NFOA) proposed by Raun and Lukina $\left(\mathrm{T}_{\mathrm{RL}}\right)$ and a simplification introduced by Li and Zhang $\left(\mathrm{T}_{\mathrm{LZ}}\right)$. It shows that when insufficient basal fertilizer was provided, the proposed method provided as much NFT as the $\mathrm{T}_{\mathrm{LF}}$ method, i.e., $25.05 \%$ or $11.88 \%$ more than the $\mathrm{T}_{\mathrm{RL}}$ and $\mathrm{T}_{\mathrm{LZ}}$ methods and increased the yields by $4.62 \%$ or $2.27 \%$, respectively; and when sufficient basal fertilizer was provided, the $\mathrm{T}_{\mathrm{HP}}$ method followed the $T_{R L}$ and $T_{L Z}$ methods to reduce NFT but maintained as much yield as the $T_{L F}$ method with a decrease of NFT by $4.20 \%$. The results prove that $\mathrm{T}_{\mathrm{HP}}$ could enhance crop production under insufficient $\mathrm{N}$ preceding conditions by prescribing more fertilizer and increase nitrogen use efficiency (NUE) by lowering the fertilizer amount when enough basal fertilizer is provided.
\end{abstract}

Keywords: topdressing optimization; UAV-based remote sensing; growth potential; winter wheat; Huang-Huai-Hai Plain

\section{Introduction}

Winter wheat is a main crop on the Huang-Huai-Hai Plain in China. Its planting area covered approximately $1.7 \times 10^{7}$ ha between 2001 and 2016 and has shown an increasing trend in recent years [1]. In winter wheat cultivation, topdressing is a widely adopted operation to boost production in the area. Currently, the nitrogen fertilizer amount for topdressing (NFT) is still mostly decided through past experience or arbitrarily without quantitative consideration of the crop growth status [2]. Topdressing usually works well to maintain high production by providing additional nutrition for the following growing stages when the basal fertilizer is insufficient. However, there is a risk of fertilizer waste and low nitrogen use efficiency (NUE) when enough basal fertilizer has already been applied because farmers tend to apply excessive NFT to lower the risk of yield reduction due to fertilizer deficiency [3]. 
Given the rate uncertainty, it might be better to consider the growth status of the winter wheat crop across fields and provide an NFT based on the estimation of final yield and the NUE [2]. Some precious studies used ground-based devices to monitor crop growing status [4,5], for example, using chlorophyll meters to obtain leaf chlorophyll content, canopy analyzers to obtain canopy size, and some specialized devices such as GreenSeeker $^{\mathrm{TM}}$ (Trimble Navigation Limited, Sunnyvale, CA, USA) to obtain normalized difference vegetation index (NDVI), and then developed matched topdressing methods based on the monitored crop parameters [6-10]. These methods greatly improve the efficiency of topdressing management, but when applied to a large area, intensive monitoring is needed to obtain detailed regional data. It is therefore labor-intensive [11].

Unmanned aerial vehicle (UAV)-based remote sensing provides a convenient approach to diagnose crop growing conditions in a quick and nondestructive way with high-quality data. Users can obtain various required infield data due to the flexibility of the UAV platform and ease of operation [12]. UAVs can be integrated with sensors of different types, such as RGB cameras, multispectral/hyperspectral cameras and LiDAR sensors, to meet different needs of monitoring [11]. In recent decades, it has been increasingly applied in nutrient monitoring and yield prediction. Matsumura [13] used two different images taken before and after the harvest period of the blue Normalized Difference Vegetation Index (BNDVI) to detect possible overfertilized areas of grassland. Zhang et al. [14] used Excess Green (ExG) colour feature extracted from a UAV-based visible image to estimate the grain yield of maize which received variable-rate $\mathrm{N}$ application. These researches indicated the potential of using UAV-based remote sensing in fertilizer management. Moreover, with the development in data processing, generating 3D point clouds from UAV-based images using the structure from motion (SfM) technology provides a new option to acquire height data, and it is a trend to use plant height to improve crop monitoring and yield prediction [15]. Bendig et al. [16] combined selected vegetation indices (VIs) and plant height information obtained from UAV-based multi-temporal crop surface models (CSMs) to estimate the biomass of summer barley using multiple linear regression or multiple non-linear regression models and found that the estimation performed better than using VIs alone. Furukawa et al. [17] used the corn height generated by 3D photogrammetry based on SfM to predict grain yield of corn, and achieved an $\mathrm{R}^{2}$ of 0.51 at the beginning of August, which solves the problem of NDVI saturation in the late growing stages. Therefore, it is a promising way for the wide application of topdressing optimization methods to adopt crop growth data acquired by UAV-based remote sensing [11].

After determining the crop growth status at topdressing, a potential growth trend and final production need to be predicted based on the current status, and then a suggested NFT is calculated in consideration of both the maximum possible yield and the NUE. Following this logic, numerous studies have provided optimization methods for topdressing. In researches using chlorophyll meter readings to guide topdressing, thresholds for specific cultivar in specific areas are usually pre-defined from previous experience, below which a reduction in yield occurs. When the monitored readings are below the thresholds, topdressing is applied at empirical amount $[8,18,19]$. Canopy size is another widely used indicator to guide topdressing. Wood et al. [9] used a target canopy green area index (GAI) to represent the growth potential, and the NFT was determined by multiplying the difference between the monitored GAI and target GAI by a canopy nitrogen requirement (CNR), where CNR is the amount of $\mathrm{N}$ fertilizer needed to produce unit GAI acquired from the previous research. These methods are concise and easy to operate with elimination in the calculation processes; however, to precisely evaluate the $\mathrm{N}$ requirements of crops, more details about the process of $\mathrm{N}$ uptake are needed. 
The nitrogen fertilization optimization algorithm (NFOA) thoroughly presents the accumulation of $\mathrm{N}$ in crops and is a widely used optimization method of topdressing [20]. In this method, NFT is determined by the difference in $\mathrm{N}$ accumulation at topdressing and harvest, and the former is estimated from the NDVI monitored at topdressing, while the latter is estimated from a predicted grain yield (PGY). However, the prediction of grain yield has always been difficult. In previous research, PGY was replaced by the best achievable grain yields in the last 4 to 5 years within a region; however, there is a risk of overestimation and excessive topdressing [21]. Subsequent studies used in-season estimates of grain yield (INSEY) to calculate PGY. INSEY is the ratio of NDVI readings collected between Feekes 4 to 6 stages, divided by the number of days from planting where growing degree days (GDD) $>0$, and it has a good exponential relationship with yield [20]. The introduction of INSEY in topdressing of winter wheat, corn and other crops improved NUE or grain yield or profit [22]. Nevertheless, these studies tend to underestimate the PGY of crops that suffered preceding nutrient stress, as they accept the assumption that $\mathrm{N}$ deficiency occurring in the early stages will continue to influence future development [21]. More appropriate estimation of growth potential is needed to take the increment that can be generated by topdressing into consideration.

The objectives of this study are to: (1) acquire accurate winter wheat growth status data at high spatial resolution for topdressing optimization using UAV-based remote sensing and (2) modify the assessment of the growth potential of winter wheat for topdressing optimization by precisely evaluating the increment of grain yield, which can be generated from the improvement in nutrition conditions.

\section{Materials and Methods}

In this study, a new topdressing method $\left(\mathrm{T}_{\mathrm{HP}}\right)$ with modified assessment of the growth potential of winter wheat was proposed. $\mathrm{T}_{\mathrm{HP}}$ was validated and compared with the local farmer's method $\left(\mathrm{T}_{\mathrm{LF}}\right)$, the NFOA method $\left(\mathrm{T}_{\mathrm{RL}}\right)$, and the simplified method $\left(\mathrm{T}_{\mathrm{LZ}}\right)$ in a field experiment using real-time, high- resolution UAV-based information.

\subsection{Topdressing Methods}

$\mathrm{T}_{\mathrm{HP}}$ is a modified topdressing method which uses a new parameter, the relative volume (RV), to estimate the growth potential. $R V$ is a direct indicator of above-ground biomass (AGB) that makes it possible to predict the accumulation of AGB. The $\mathrm{T}_{\mathrm{HP}}$ method provides more basis for the management of topdressing than methods using NDVI alone.

The calculation steps of the four topdressing methods used in this study are shown in Figure 1. For $\mathrm{T}_{\mathrm{LF}}, 76 \mathrm{~kg} \cdot \mathrm{N} \cdot \mathrm{ha}^{-1}$, fertilizer is applied to the whole field regardless of the winter wheat growth status, while for $\mathrm{T}_{\mathrm{HP}}, \mathrm{T}_{\mathrm{RL}}$ and $\mathrm{T}_{\mathrm{LZ}}$, the recommendations of NFT are based on the growth status monitored by UAV-based remote sensing.

\subsection{1. $\mathrm{T}_{\mathrm{HP}}$ - Method Based on Improved Growth Estimation}

$\mathrm{T}_{\mathrm{HP}}$ used RV to estimate AGB of winter wheat at topdressing period and for further prediction of AGB at harvest, where RV is the product of plant height $(\mathrm{H})$ and coverage (C). The acquisition of plant height and UAV-based information will be introduced in Sections 2.3 and 2.4, respectively. The calculation processes are as follow. Additionally, the formulas used in the calculation processes were derived from an ancillary experiment which will be introduced in Section 2.2. 


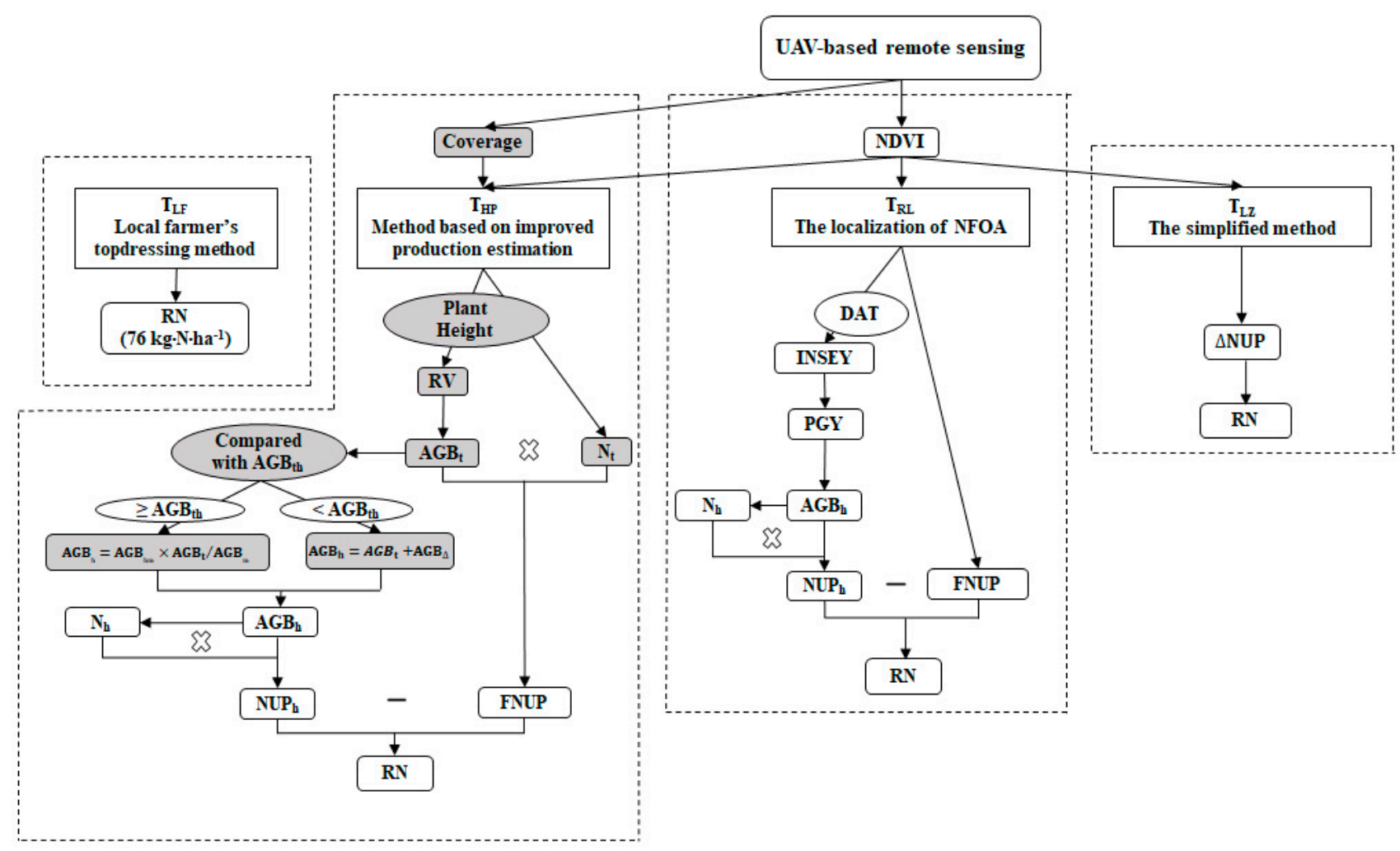

Figure 1. Calculation steps of 4 topdressing methods for winter wheat. $\left(T_{H P}, T_{R L}, T_{L Z}\right.$ and $T_{L F}$ are different topdressing methods; RN: recommended nitrogen fertilizer amount for topdressing, RV: relative volume, AGB: above ground biomass, $\mathrm{N}_{\mathrm{t}}$ : nitrogen concentration in aboveground part at topdressing period, $\mathrm{N}_{\mathrm{h}}$ : nitrogen concentration in aboveground part at harvest, INSEY: in-season estimates of grain yield, PGY: predicted grain yield, FNUP: forage nitrogen uptake, NUP: N uptake in the aboveground part; the subscripts represent different times, i.e., $t$ represents topdressing and $h$ represents harvest, except for $\mathrm{AGB}_{\text {th }}$, which represents a threshold of $\mathrm{AGB}$ at topdressing).

(1) Calculation of the AGB-related parameter RV (cm):

$$
\mathrm{RV}=\mathrm{H} \times \mathrm{C} / 100
$$

where $\mathrm{H}$ is the plant height $(\mathrm{cm})$ of winter wheat during the topdressing period and $\mathrm{C}$ is the coverage (\%) of winter wheat extracted from UAV-based remote sensing images taken at the same time.

(2) Estimation of $\mathrm{AGB}$ of winter wheat in the topdressing period $\left(\mathrm{AGB}_{\mathrm{t}}, \mathrm{Mg} \cdot \mathrm{ha}{ }^{-1}\right)$ from RV:

$$
\mathrm{AGB}_{\mathrm{t}}=0.90 \times \ln (\mathrm{RV})-0.58
$$

(3) Estimation of nitrogen concentration in the aboveground part (NCA) of the topdressing period $\left(\mathrm{N}_{\mathrm{t}}, \mathrm{g} \cdot \mathrm{kg}^{-1}\right)$ :

$$
\mathrm{N}_{\mathrm{t}}=7.08 \times \mathrm{e}^{1.31 \times \mathrm{NDVI}}
$$

(4) The forage $\mathrm{N}$ uptake of the topdressing period (FNUP, $\mathrm{kg} \cdot \mathrm{ha}^{-1}$ ) was calculated as follows:

$$
\mathrm{FNUP}_{\mathrm{AGB}}=\mathrm{AGB}_{\mathrm{t}} \times \mathrm{N}_{\mathrm{t}}
$$

(5) Determination of AGB of harvest time $\left(\mathrm{AGB}_{\mathrm{h}}, \mathrm{Mg} \cdot \mathrm{ha}^{-1}\right)$ :

$$
\left\{\begin{array}{c}
\mathrm{AGB}_{\mathrm{h}}=\mathrm{AGB}_{\mathrm{hm}} \times \mathrm{AGB}_{\mathrm{t}} / \mathrm{AGB}_{\mathrm{m}}\left(\mathrm{AGB}_{\mathrm{t}} \geq \mathrm{AGB}_{\mathrm{th}}\right) \\
\mathrm{AGB}_{\mathrm{h}}=\mathrm{AGB}_{\mathrm{t}}+\mathrm{AGB}_{\Delta}\left(\mathrm{AGB}_{\mathrm{t}}<\mathrm{AGB}_{\mathrm{th}}\right)
\end{array}\right.
$$


where $\mathrm{AGB}_{\mathrm{hm}}\left(13.00 \mathrm{Mg} \cdot \mathrm{ha}^{-1}\right)$ is the AGB at the harvest time of winter wheat, which received adequate nitrogen during the entire growing period, $\mathrm{AGB}_{\mathrm{m}}\left(2.15 \mathrm{Mg} \cdot \mathrm{ha}^{-1}\right)$ is the AGB during the topdressing period of winter wheat, which received adequate nitrogen before topdressing, $\mathrm{AGB}_{\text {th }}\left(2.03 \mathrm{Mg} \cdot \mathrm{ha}^{-1}\right)$ is a threshold to judge whether winter wheat is under nitrogen deficiency during the topdressing period and $\mathrm{AGB}_{\Delta}$ $\left(10.50 \mathrm{Mg} \cdot \mathrm{ha}^{-1}\right)$ is the maximum increment of AGB from topdressing to harvest:

$$
\mathrm{AGB}_{\Delta}=0.9 \times\left(\mathrm{AGB}_{\mathrm{hm}}-\mathrm{AGB}_{0}\right)
$$

where $\mathrm{AGB}_{0}\left(1.33 \mathrm{Mg} \cdot \mathrm{ha}^{-1}\right)$ is the $\mathrm{AGB}$ during the topdressing period of winter wheat that received no nitrogen fertilizer.

(6) Estimation of NCA of the harvest period $\left(\mathrm{N}_{\mathrm{h}}, \mathrm{g} \cdot \mathrm{kg}^{-1}\right)$ :

$$
\mathrm{N}_{\mathrm{h}}=0.15 \times \mathrm{AGB}_{\mathrm{h}}{ }^{2}-3.27 \times \mathrm{AGB}_{\mathrm{h}}+27.88
$$

(7) Calculation of aboveground $\mathrm{N}$ uptake of harvest period $\left(\mathrm{NUP}_{\mathrm{h}}, \mathrm{kg} \cdot \mathrm{ha}^{-1}\right)$ :

$$
\mathrm{NUP}_{\mathrm{h}}=\mathrm{AGB}_{\mathrm{h}} \times \mathrm{N}_{\mathrm{h}}
$$

(8) Recommendation of NFT (RN, $\left.\mathrm{kg} \cdot \mathrm{N} \cdot \mathrm{ha}^{-1}\right)$ :

$$
\mathrm{RN}=\left(\mathrm{NUP}_{\mathrm{h}}-\mathrm{FNUP}_{\mathrm{AGB}}\right) \times 0.88
$$

A constant of 0.88 was used to reflect the soil nitrogen supply from the topdressing to the harvest period and the nitrogen usage efficiency.

\subsection{2. $\mathrm{T}_{\mathrm{RL}}$ - Method Based on Localized NFOA}

This method is a localization of NFOA, as the parameters of formulas used in NFOA are acquired from the auxiliary experiment mentioned above. The calculation processes are as follows:

(1) Calculation of INSEY:

$$
\mathrm{INSEY}=\frac{\mathrm{NDVI}}{\mathrm{DAT}}
$$

where DAT is the days from planting to monitoring, where growing degree days (GDD) $>0 ; \mathrm{GDD}=\frac{\mathrm{T}_{\max }+\mathrm{T}_{\min }}{2}-4.4^{\circ} \mathrm{C}$, where $\mathrm{T}_{\max }$ and $\mathrm{T}_{\min }$ represent daily ambient high and low temperatures [20]. In this study, the DAT $=88 \mathrm{~d}$.

(2) Estimation of PGY $\left(\mathrm{Mg} \cdot \mathrm{ha}^{-1}\right)$ based on current nutritional status:

$$
\text { PGY }=0.66 \times \mathrm{e}^{235.43 \times \mathrm{INSEY}}
$$

(3) Estimation of FNUP from NDVI (FNUP NDVI $\left._{1} \mathrm{~kg} \cdot \mathrm{ha}^{-1}\right)$ :

$$
\text { FNUP }_{\text {NDVI }}=1.03 \times \mathrm{e}^{4.50 \times \mathrm{NDVI}}
$$

(4) Calculation of the aboveground biomass at harvest $\left(\mathrm{AGB}_{\mathrm{h}}, \mathrm{Mg} \cdot \mathrm{ha}^{-1}\right)$ :

$$
\mathrm{AGB}_{\mathrm{h}}=2.00 \times \mathrm{PGY}
$$

A constant of 2.00 is used because the grain yield accounts for half of the $\mathrm{AGB}_{\mathrm{h}}[19,20]$. The following steps are the same as those in $\mathrm{T}_{\mathrm{HP}}$. We used $\mathrm{NUP}_{\mathrm{h}}$ to replace the grain $\mathrm{N}$ uptake (GNUP) used in NFOA because the straw was removed in this cropping system. The nitrogen in straw should also be considered.

\subsection{3. $\mathrm{T}_{\mathrm{LZ}}$ - Method Based on Simplified Estimation of Nitrogen Uptake}

This method calculates NFT directly from NDVI monitored during the topdressing period, and the calculation processes are as follows: 
(1) Estimation of the $\mathrm{N}$ uptake from topdressing to harvest period $\left(\Delta \mathrm{NUP}, \mathrm{kg} \cdot \mathrm{ha}^{-1}\right)$ :

$$
\Delta \mathrm{NUP}=67.75 \times \mathrm{NDVI}^{2}+55.51 \times \mathrm{NDVI}+80.45
$$

(2) Recommendation of NFT ( RN, $\left.\mathrm{kg} \cdot \mathrm{N} \cdot \mathrm{ha}^{-1}\right)$ :

$$
\mathrm{RN}_{\mathrm{LZ}}=\Delta \mathrm{NUP} \times 0.88
$$

The parameters were also acquired from the ancillary experiment introduced above.

\subsection{Field Experiment}

The field experiment was arranged at the Fengqiu Agro-ecological Experimental Station, Chinese Academy of Sciences $\left(114^{\circ} 34^{\prime}\right.$ E, $\left.35^{\circ} 01^{\prime} \mathrm{N}\right)$ in Fengqiu County (Henan Province, China), between October 2018 and June 2019 (Figure 2). A completely randomized design was used in the experiment with five topdressing methods at three levels of preceding nutrient conditions. The topdressing methods included the $\mathrm{T}_{\mathrm{HP}}, \mathrm{T}_{\mathrm{LF}}, \mathrm{T}_{\mathrm{RL}}$, $\mathrm{T}_{\text {LZ }}$ methods and a control $\left(\mathrm{T}_{0}\right)$ with $0 \mathrm{~kg} \cdot \mathrm{ha}^{-1}$ topdressing $\mathrm{N}$ fertilizer, and the three preceding nutrient conditions were achieved by applying controlled $\mathrm{N}$ basal fertilizers: $\mathrm{B}_{0}$ $\left(0 \mathrm{~kg} \cdot \mathrm{N} \cdot \mathrm{ha}^{-1}\right), \mathrm{B}_{1}\left(57 \mathrm{~kg} \cdot \mathrm{N} \cdot \mathrm{ha}^{-1}\right)$ and $\mathrm{B}_{2}\left(114 \mathrm{~kg} \cdot \mathrm{N} \cdot \mathrm{ha}^{-1}\right)$, where $\mathrm{B}_{2}$ basal rates describe approximate rates used by many farmers in the region. Each treatment had 4 replications, and in total, there were 60 experimental units in the experiment. The units were $16 \mathrm{~m}^{2}$ $(4 \mathrm{~m} \times 4 \mathrm{~m})$. Phosphorus and potassium fertilizers were applied without treatments at $130 \mathrm{~kg} \cdot \mathrm{P}_{2} \mathrm{O}_{5} \cdot \mathrm{ha}^{-1}$ in the form of $\mathrm{Ca}\left(\mathrm{H}_{2} \mathrm{PO}_{4}\right)_{2}$ and $120 \mathrm{~kg} \cdot \mathrm{K}_{2} \mathrm{O} \cdot \mathrm{ha}{ }^{-1}$ in the form of $\mathrm{K}_{2} \mathrm{SO}_{4}$ as basal fertilizers. Nitrogen fertilizers were applied in the form of urea for basal and topdressing. In the entire growing stage, we carried out irrigation in four time periodsbefore sowing (October 21st), after topdressing (March 24th), booting (April 17th) and milk ripening (May14th). The irrigation amount was 60, 30, 50 and $50 \mathrm{~mm}$, respectively (Figure 3).

(a)

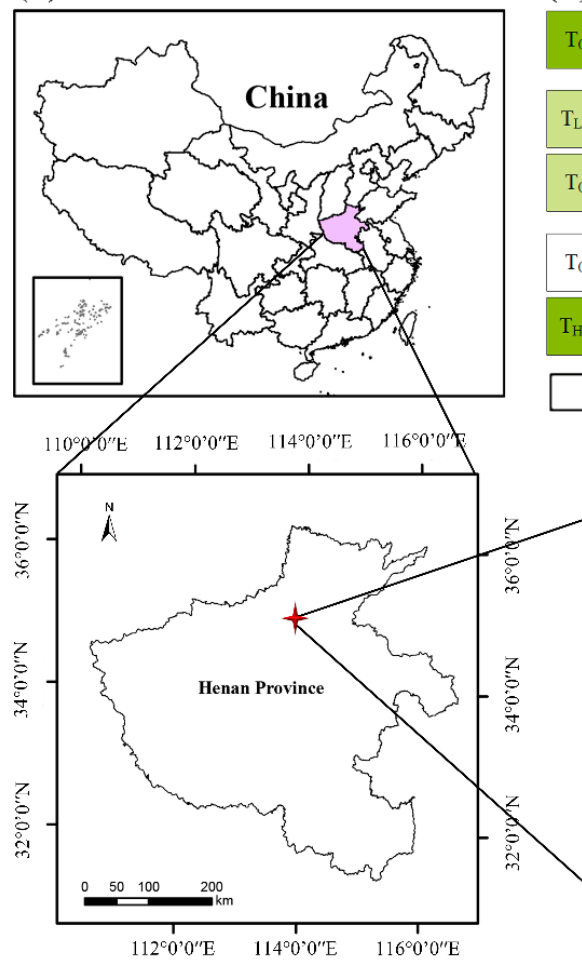

(b)

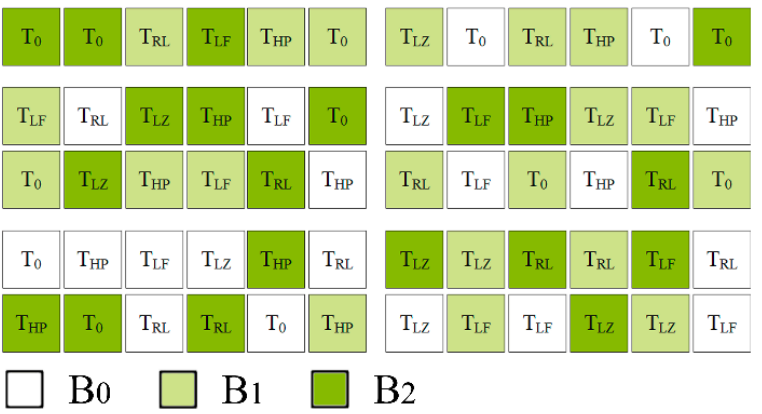

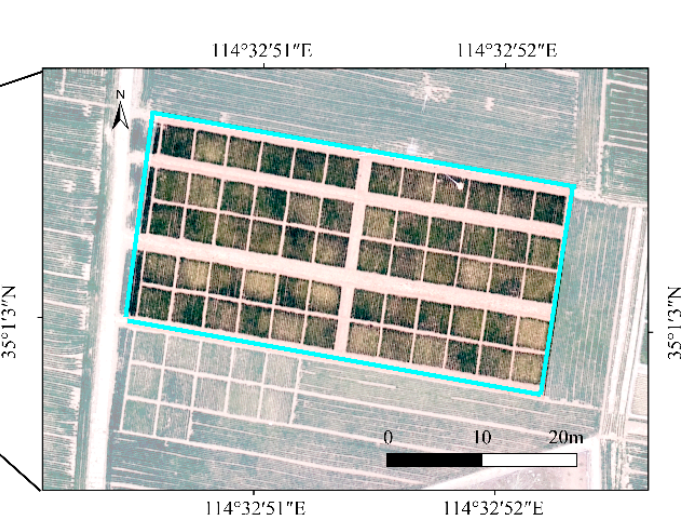

Figure 2. Study site and the experimental design. (a) The location of the Fengqiu Agro-ecological experimental station, CAS. (b) Experimental design $\left(\mathrm{T}_{\mathrm{HP}}, \mathrm{T}_{\mathrm{LF}}, \mathrm{T}_{\mathrm{RL}}, \mathrm{T}_{\mathrm{LZ}}\right.$ and $\mathrm{T}_{0}$ are different topdressing methods, and basal fertilizer levels $\left(\mathrm{B}_{0}, \mathrm{~B}_{1}\right.$ and $\mathrm{B}_{2}$ ) are represented by different colors). 


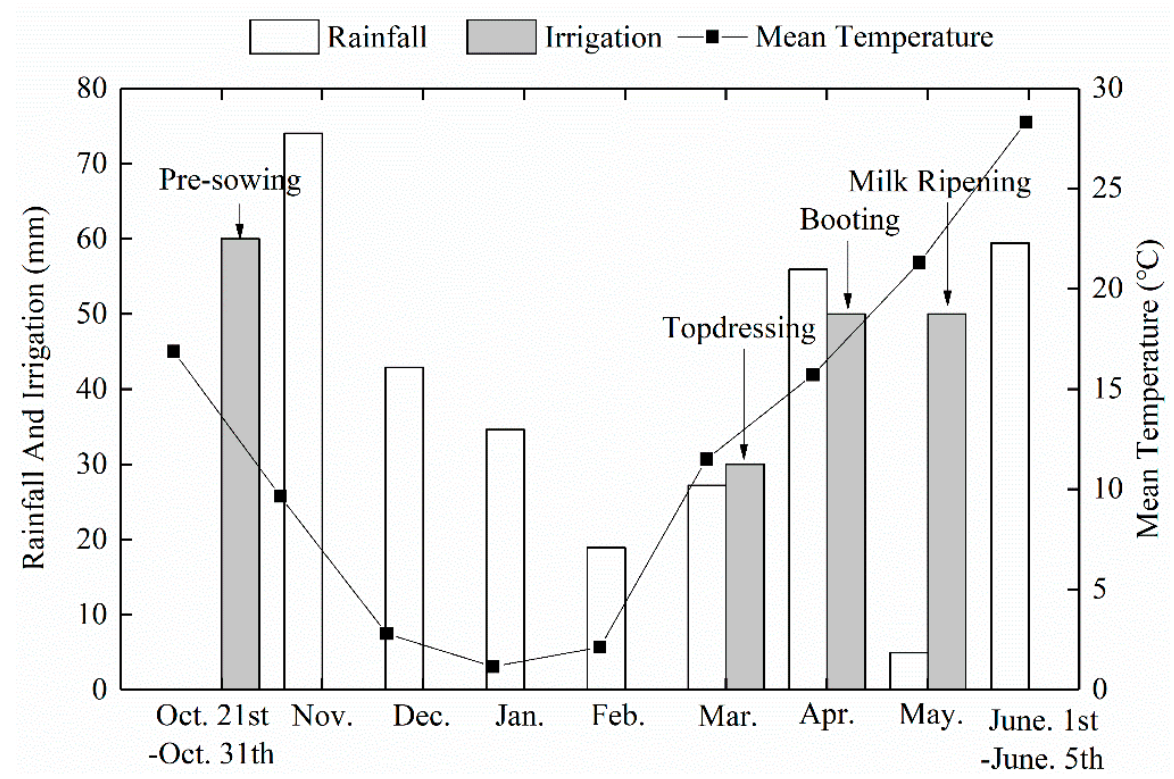

Figure 3. Rainfall and irrigation and mean temperature recorded during the 2018 to 2019 wheat growing seasons in Fengqiu Agro-ecological experimental station, CAS.

The experimental site has a typical monsoon climate with a mean annual temperature of $13.5 \sim 14.5{ }^{\circ} \mathrm{C}$ and the mean temperature for the entire growing season was $9.9{ }^{\circ} \mathrm{C}$. The mean annual precipitation is $615 \mathrm{~mm}$ and is mainly concentrated between July and September. For the growing season of winter wheat, the precipitation was $318 \mathrm{~mm}$, the specific temperature and precipitation information is shown in Figure 3. The annual sunshine hours are approximately $2300 \sim 2500 \mathrm{~h}$, and the frost-free period is approximately 214 days. The soil is classified as Calcaric Fluvisol according to the FAO, with an average $\mathrm{pH}$ of 8.3 , bulk density of $1.44 \mathrm{~g} \cdot \mathrm{cm}^{-3}$, porosity of $0.46 \mathrm{~cm}^{3} \cdot \mathrm{cm}^{-3}, 6.09 \mathrm{~g} \cdot$ organic $\mathrm{C} \cdot \mathrm{kg}^{-1}$, $0.55 \mathrm{~g} \cdot$ total $\mathrm{N} \cdot \mathrm{kg}^{-1}, 0.81 \mathrm{~g} \cdot$ total $\mathrm{P} \cdot \mathrm{kg}^{-1}, 18.08 \mathrm{~g} \cdot$ total $\mathrm{K} \cdot \mathrm{kg}^{-1}$, and $8.01 \mathrm{cmol}$ cation exchange capacity (CEC) $\cdot \mathrm{kg}^{-1}$ [21-24]. Winter wheat (Bainong Aikang 58) was sown on 24 October 2018 and harvested on 05 June 2019, and topdressing was applied on 24 March 2019.

Apart from the topdressing experiment, an ancillary experiment with five nitrogen levels, applying $\mathrm{N}_{0}: 0, \mathrm{~N}_{1}: 150, \mathrm{~N}_{2}: 190, \mathrm{~N}_{3}: 230, \mathrm{~N}_{4}: 270 \mathrm{~kg} \cdot \mathrm{N} \cdot \mathrm{ha}^{-1}$ fertilizer throughout the entire growing period ( $60 \%$ as the basal fertilizer and $40 \%$ as topdressing) was conducted. As the $190 \mathrm{~kg} \cdot \mathrm{N} \cdot \mathrm{ha}^{-1}$ fertilizer is approximate rates used by many farmers in the region, fertilizer levels of 190,230 , and $270 \mathrm{~kg} \cdot \mathrm{N} \cdot \mathrm{ha}^{-1}$ are considered adequate. The size of the experiment unit was $48 \mathrm{~m}^{2}(8 \mathrm{~m} \times 6 \mathrm{~m})$ and units were separated by concrete slabs to prevent lateral exchange of soil solutions. The other field managements were the same as those for the topdressing experiment.

\subsection{Plant Sampling and Measurement}

In this study, plant height, $A G B, N$ concentration in the aboveground part (NCA), and chlorophyll concentration were continuously investigated before and after topdressing to indicate the effect of each topdressing method. In addition, grain yield and straw biomass were measured at harvest. It is worth mentioning that plant height at topdressing is also a key parameter to calculate NFT in $\mathrm{T}_{\mathrm{HP}}$.

Plant samplings were conducted at four growth stages in 2019-reviving (21 March), booting (16 April), anthesis (28 April) and milk ripening (18 May)_because reviving is the critical growth stage for topdressing, while booting, anthesis and milk ripening are pivotal growth stages of yield formation. Winter wheat was randomly sampled from four corners and the center of the plot (a total of five sampling points for each plot). For the measurement of plant height and chlorophyll concentration, one plant from each sampling point was picked, and the plant height was manually measured with meter scale, while chlorophyll concentration was measured with an MC-100 chlorophyll concentration meter 
(Apogee Instruments, Inc., Logan, UT, USA). For each plot, all sampled plants were dried and weighed for the measurement of AGB, and the dry matter was crushed and sieved to test NCA using the Kjeldahl method [23]. At maturity (5 June 2019), wheat plants in an area of $1 \mathrm{~m}^{2}$ were harvested. The grain and straw were separated, dried and weighed to measure grain yield and straw biomass [24].

\subsection{UAV-Based Remote Sensing}

High-resolution RGB and multispectral images of the experimental area were captured on 21 March 2019 before topdressing by an RGB (Zenmuse X5S, DJI, Shenzhen, China) and a multispectral camera (Rededge-M, MicaSense, Seattle, WA, USA) mounted on a quadcopter UAV (M210, DJI), respectively. The work was done between 10:00 and 14:00 local time while it was cloudless and the solar radiation intensity was stable. A regular grid flying pattern was specified to assure over $70 \%$ of the image overlapped along and perpendicular to the flight direction, with the flight altitude maintained at $100 \mathrm{~m}$ aboveground. Orthographic maps of RGB and multispectral images were generated by Pix4Dmapper 4.2.27 (Pix4D SA, Lausanne, Switzerland) after optical corrections.

In this study, the parameters required by the topdressing methods from UAV-based remote sensing include crop coverage and NDVI:

$$
\mathrm{NDVI}=\frac{\mathrm{R}_{\mathrm{NIR}}-\mathrm{R}_{\mathrm{Red}}}{\mathrm{R}_{\mathrm{NIR}}+\mathrm{R}_{\mathrm{Red}}}
$$

where $R_{\text {NIR }}$ is the reflectance of near IR band, $R_{\text {red }}$ is the reflectance of red band [21].

Crop NDVI of the plots was extracted from the multispectral orthographic map [25], while crop coverages of the plots were calculated from the RGB orthographic map by a method using threshold of vegetation index decided by human interpreting to divide crop and soil [26-28]. The vegetation index used for crop coverage extraction was the normalized difference greenness index (NDGI), as NDGI is sensitive to the canopy biomass and vegetation fraction or leaf area [29]:

$$
\mathrm{NDGI}=\frac{\mathrm{DN}_{\text {green }}-\mathrm{DN}_{\text {red }}}{\mathrm{DN}_{\text {green }}+\mathrm{DN}_{\text {red }}}
$$

where $\mathrm{DN}_{\text {green }}$ is the digital number of the green band and $\mathrm{DN}_{\text {red }}$ is the digital number of the red band.

\subsection{Evaluation of NFT Use Efficiency}

Partial factor productivity from applied $\mathrm{N}$ for topdressing $\left(\mathrm{PFP}_{\mathrm{t}}\right)$ was used to evaluate the profit and return from $\mathrm{N}$ applied as topdressing, and it refers to the calculation formula of partial factor productivity from applied $\mathrm{N}\left(\mathrm{PFP}_{\mathrm{N}}\right)[30]$ :

$$
\operatorname{PFP}_{\mathrm{N}}=\frac{\mathrm{Y}}{\mathrm{N}_{\mathrm{T}}}
$$

where $\mathrm{Y}\left(\mathrm{Mg} \cdot \mathrm{ha}^{-1}\right)$ is the grain yield and $\mathrm{N}_{\mathrm{T}}\left(\mathrm{kg} \cdot \mathrm{N} \cdot \mathrm{ha}^{-1}\right)$ is the total $\mathrm{N}$ fertilizer amount applied, including basal and topdressing:

$$
\mathrm{PFP}_{\mathrm{t}}=\frac{\mathrm{Y}-\mathrm{Y}_{0}}{\mathrm{NFT}}
$$

where $\mathrm{Y}_{0}\left(\mathrm{Mg} \cdot \mathrm{ha}^{-1}\right)$ is the grain yield of the treatment that received a certain amount of nitrogen as basal fertilizer without topdressing. NFT $\left(\mathrm{kg} \cdot \mathrm{N} \cdot \mathrm{ha}^{-1}\right)$ is the nitrogen fertilizer amount of topdressing under a certain basal fertilizer level. 


\section{Results \\ 3.1. Growth Status of Winter Wheat Before Topdressing}

The growth status of winter wheat varied significantly under different early nutrient conditions before topdressing (Table 1). Growth status under $B_{2}$ represented the growth of winter wheat under local farmer's growing conditions. Compared to $B_{2}$, the plant height, AGB, chlorophyll concentration, and NCA of $\mathrm{B}_{0}$ decreased by $22.73 \%, 24.01 \%, 16.70 \%$ and $21.28 \%$, respectively; for $\mathrm{B}_{1}$, these parameters decreased by $8.32 \%, 14.08 \%, 7.74 \%$, and $8.71 \%$, respectively.

Table 1. Growth status of winter wheat under different basal fertilizer levels before topdressing.

\begin{tabular}{|c|c|c|c|c|}
\hline $\begin{array}{c}\text { Growth } \\
\text { Parameters }\end{array}$ & $\begin{array}{l}\text { Plant Height } \\
\text { (cm) }\end{array}$ & 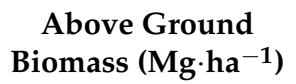 & $\begin{array}{c}\text { Chlorophyll Concentration } \\
\left(\mu \mathrm{mol} \cdot \mathrm{m}^{-2}\right)\end{array}$ & $\begin{array}{l}\text { Nitrogen Concentration in } \\
\text { Above Ground Part }\left(\mathrm{g} \cdot \mathrm{kg}^{-1}\right)\end{array}$ \\
\hline $\mathrm{B}_{0}$ & $19.33 \pm 1.81(\mathrm{c})$ & $1.59 \pm 0.06(\mathrm{c})$ & $540.79 \pm 11.39$ (c) & $18.05 \pm 0.55(\mathrm{c})$ \\
\hline $\mathrm{B}_{1}$ & $22.94 \pm 2.85(\mathrm{~b})$ & $1.80 \pm 0.05(b)$ & $598.94 \pm 13.77(b)$ & $20.93 \pm 0.47(b)$ \\
\hline $\mathrm{B}_{2}$ & $25.02 \pm 2.04(\mathrm{a})$ & $2.10 \pm 0.06(\mathrm{a})$ & $649.18 \pm 15.01(\mathrm{a})$ & $22.93 \pm 0.66(a)$ \\
\hline
\end{tabular}

$\mathrm{B}_{0}, \mathrm{~B}_{1}$ and $\mathrm{B}_{2}$ represent basal fertilizer levels of 0,57 , and $114 \mathrm{~kg} \cdot \mathrm{N} \cdot \mathrm{ha}^{-1}$, respectively; different letters indicate significance within the same column using Fischer's protected least significant difference at $p<0.05$.

UAV-based images (Figure 4) intuitively presented the difference in winter wheat under different basal fertilizer levels at topdressing; correspondingly, the unit average NDVI and coverage of winter wheat varied significantly (Table 2). The difference in coverage was especially obvious. The unit average coverage of winter wheat under $B_{0}$ and $B_{1}$ was $34.58 \%$ and $13.65 \%$ lower than that under $B_{2}$, respectively. The unit average NDVI under $\mathrm{B}_{0}$ and $\mathrm{B}_{1}$ was $9.41 \%$ and $2.35 \%$ lower than that under $\mathrm{B}_{2}$, respectively.

(a)

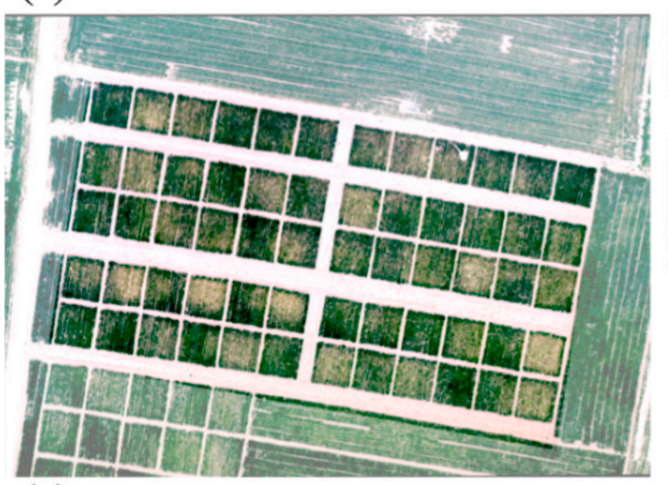

(b)

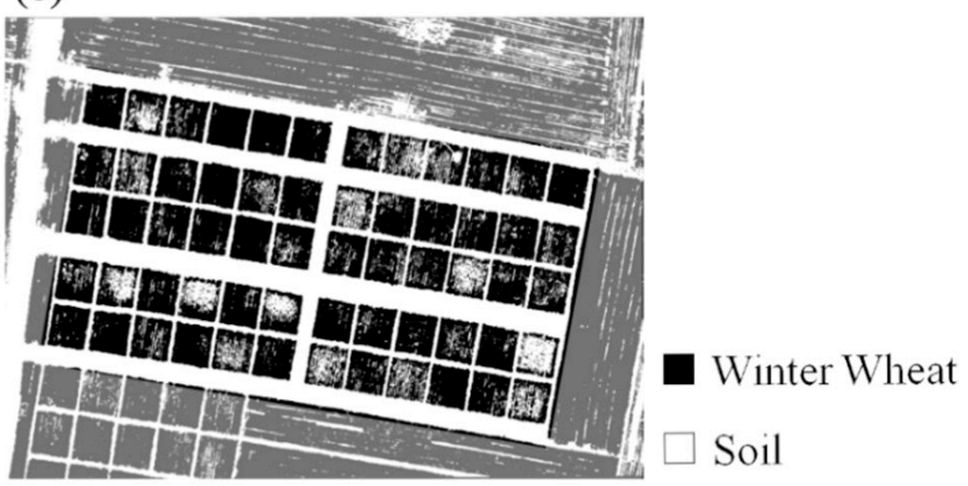

(c)

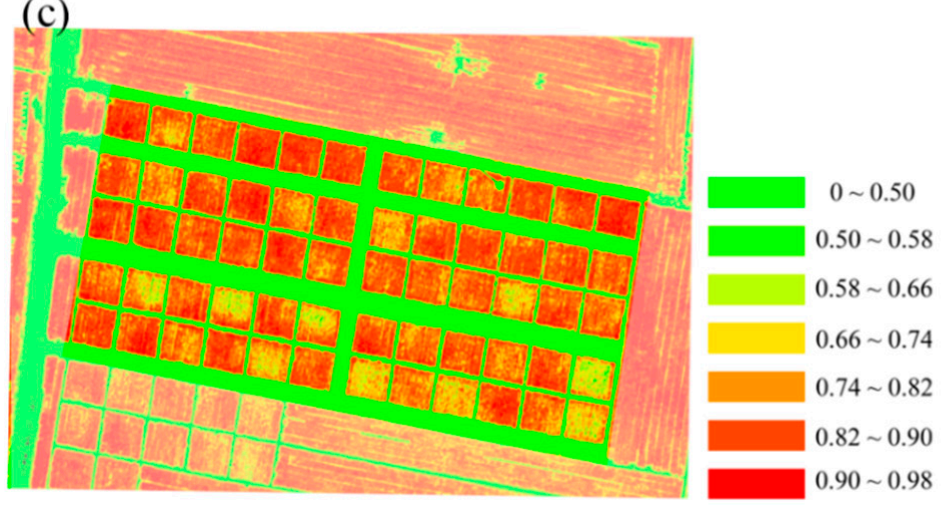

Figure 4. UAV-based images of winter wheat under different basal fertilizer levels. (a) RGB. (b) NDVI. (c) Coverage. 
Table 2. Average NDVI and coverage of winter wheat under different basal fertilizer levels.

\begin{tabular}{ccc}
\hline Remote Sensing Information & NDVI & Coverage \\
\hline $\mathrm{B}_{0}$ & $0.77 \pm 0.04(\mathrm{c})$ & $49.99 \% \pm 9.76 \%(\mathrm{c})$ \\
$\mathrm{B}_{1}$ & $0.83 \pm 0.02(\mathrm{~b})$ & $65.98 \% \pm 6.99 \%(\mathrm{~b})$ \\
$\mathrm{B}_{2}$ & $0.85 \pm 0.02(\mathrm{a})$ & $76.41 \% \pm 6.62 \%(\mathrm{a})$ \\
\hline
\end{tabular}

$\mathrm{B}_{0}, \mathrm{~B}_{1}$ and $\mathrm{B}_{2}$ represent basal fertilizer levels of 0,57 and $114 \mathrm{~kg} \cdot \mathrm{N} \cdot \mathrm{ha}^{-1}$, respectively; different letters indicate significance within the same column using Fischer's protected least significant difference at $p<0.05$.

\subsection{Recommendations of NFT}

The experimental unit average NDVI and coverage of winter wheat extracted in 3.1 and measured plant height were substituted into the formulas (Section 2.1) obtained from the auxiliary experiment (Figure 5) to generate the NFT recommendations. The specific NFT for each unit is shown in Figure 6. The statistical results of the recommended NFT for each topdressing method under different basal fertilizer conditions are shown in Figure 7.

(a)
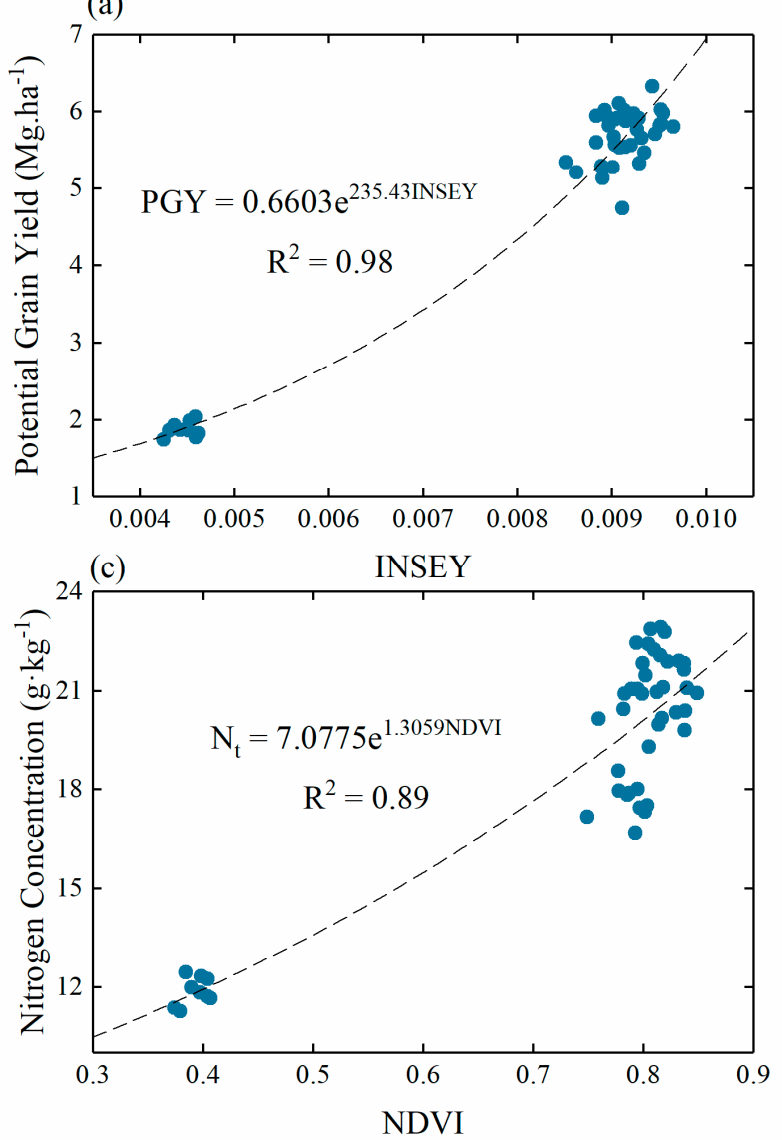

(b)
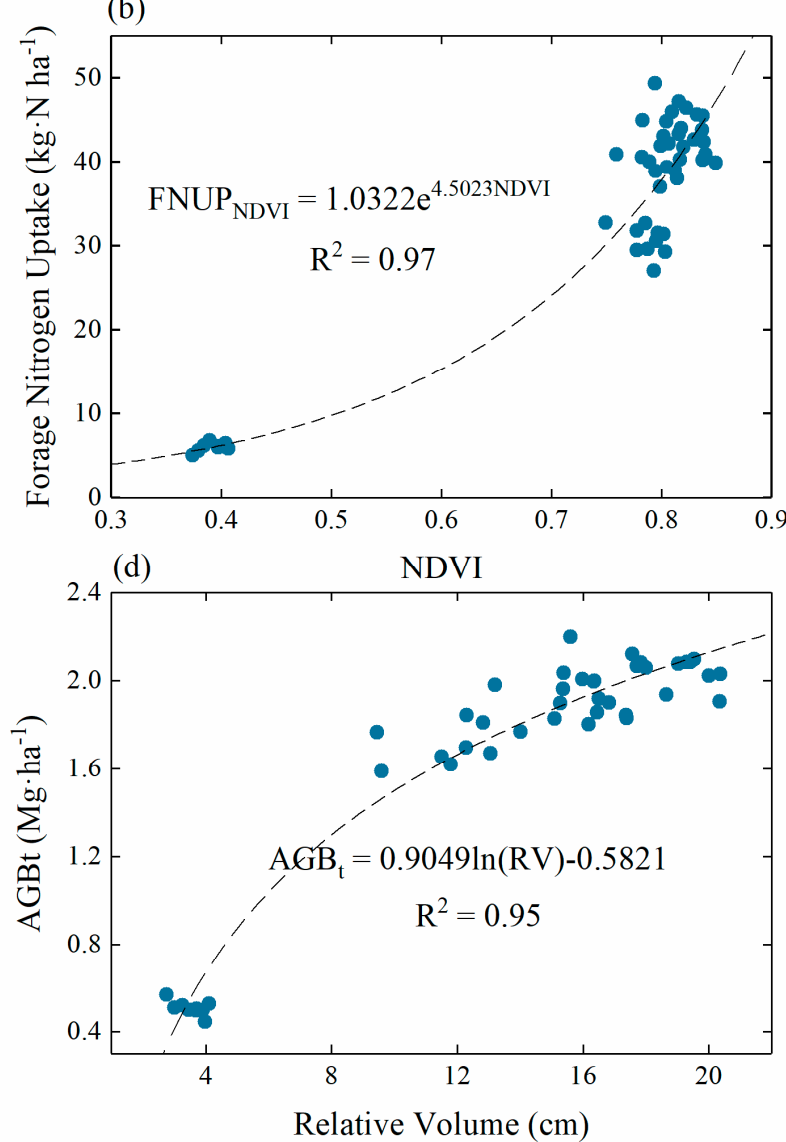

Figure 5. Illustration of formulas used in $\mathrm{T}_{\mathrm{HP}}, \mathrm{T}_{\mathrm{RL}}$ and $\mathrm{T}_{\mathrm{LZ}}$ obtained from the auxiliary experiment. (a) Predicting potential grain yield (PGY) from INSEY (in-season estimate of grain yield). (b) Predicting forage nitrogen uptake (FNU $\mathrm{NDVI}_{\mathrm{N}}$ ) from the normalized difference vegetation index (NDVI). (c) Predicting nitrogen concentration in the aboveground part at topdressing $\left(\mathrm{N}_{\mathrm{t}}\right)$ from NDVI. (d) Predicting aboveground biomass at topdressing, $\mathrm{AGB}_{\mathrm{t}}$ from relative volume. 


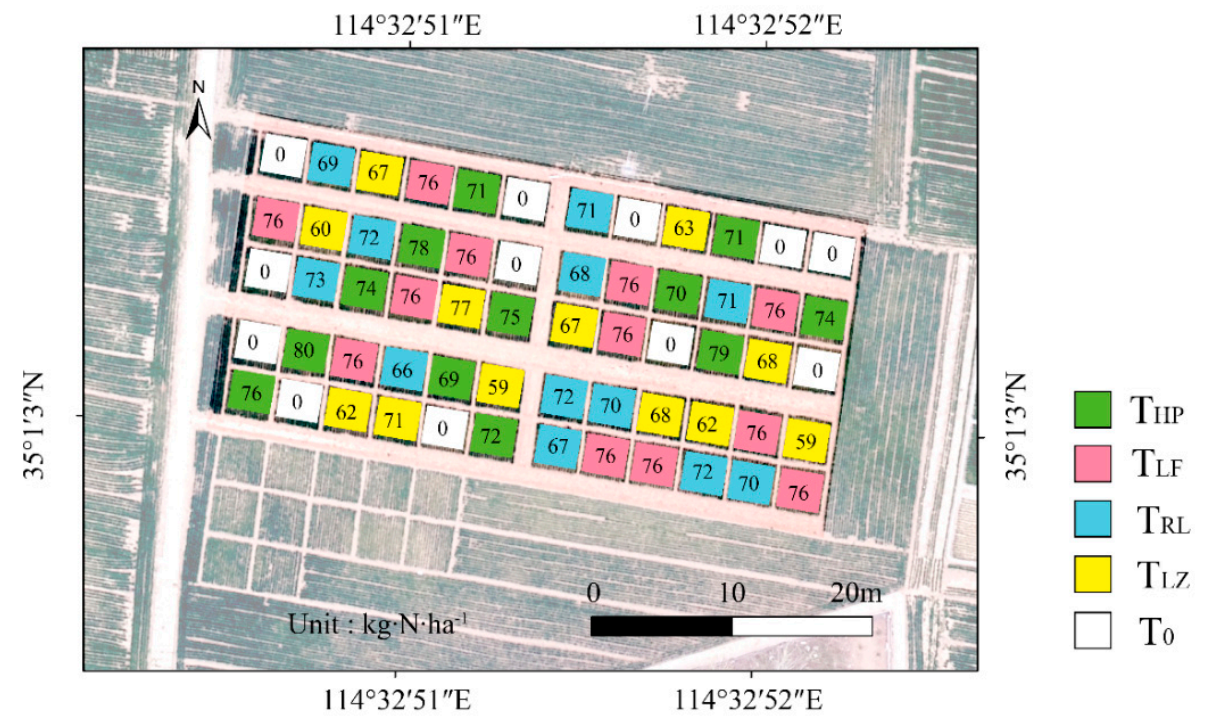

Figure 6. Recommended nitrogen fertilizer amount for topdressing for each unit. $\left(\mathrm{T}_{\mathrm{HP}}, \mathrm{T}_{\mathrm{LF}}, \mathrm{T}_{\mathrm{RL}}\right.$, $\mathrm{T}_{\mathrm{LZ}}$, and $\mathrm{T}_{0}$ represent different topdressing methods).
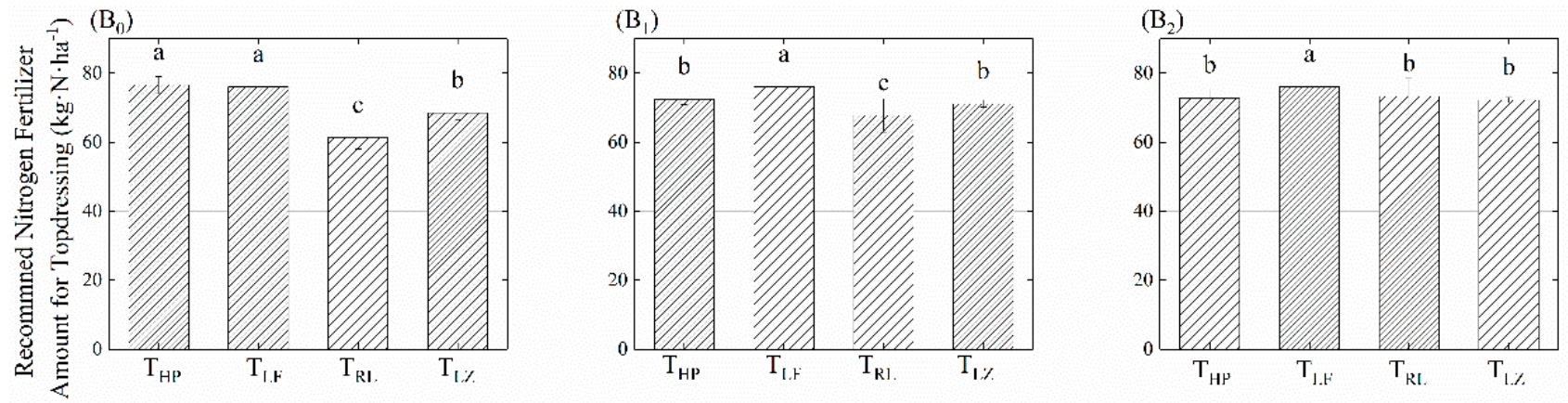

Figure 7. Recommended nitrogen fertilizer amount for topdressing under different basal fertilizer levels. $\left(B_{0}, B_{1}\right.$ and $B_{2}$ represent basal fertilizer levels of 0,57 and $114 \mathrm{~kg} \cdot \mathrm{ha}^{-1}$, respectively; $\mathrm{T}_{\mathrm{HP}}, \mathrm{T}_{\mathrm{LF}}, \mathrm{T}_{\mathrm{RL}}$, and $\mathrm{T}_{\mathrm{LZ}}$ represent different topdressing methods; different letters indicate significance using Fischer's protected least significant difference at $p<0.05$ ).

$\mathrm{T}_{\mathrm{HP}}$ tended to increase NFT when N deficiency was present in the early growing season, and recommended a moderate NFT reduction when $\mathrm{N}$ was sufficient in the early growing season. When $\mathrm{N}$ was severely deficient during the early growing stage $\left(\mathrm{B}_{0}\right), \mathrm{T}_{\mathrm{HP}}$ recommended the same NFT as $\mathrm{T}_{\mathrm{LF}}$ to compensate for the nutrient deficiency, while $\mathrm{T}_{\mathrm{RL}}$ and $\mathrm{T}_{\mathrm{LZ}}$ recommended reducing NFT by $14.42 \%$ and $9.94 \%$, respectively, due to the low expectations of growing potential. Under the $\mathrm{B}_{1}$ condition, $\mathrm{T}_{\mathrm{HP}}, \mathrm{T}_{\mathrm{RL}}$ and $\mathrm{T}_{\mathrm{LZ}}$ recommended decreasing NFT by $4.61 \%, 10.81 \%$ and $6.39 \%$ compared to $\mathrm{T}_{\mathrm{LF}}$, respectively, due to the difference in the evaluation of the nutritional conditions of crops. When sufficient basal fertilizer was provided $\left(B_{2}\right)$, the $T_{H P}$ method followed the $T_{R L}$ and $T_{L Z}$ methods to reduce NFT by $4.2 \%, 3.6 \%$ and $4.9 \%$, respectively, compared to $\mathrm{T}_{\mathrm{LF}}$.

\subsection{Responses of Winter Wheat after Topdressing}

For the further understanding of the effects of NFTs recommended by each topdressing method to the growth of winter wheat, AGB, plant height, NCA and chlorophyll concentration were continuously monitored at booting, anthesis and milk ripening stage. We compared the parameters of the four topdressing methods and a control under different base nutrition levels separately. The cumulative graphs of each growth parameter (Figure 7) illustrated the developing process of winter wheat intuitively, as the developing trend for each growth parameter over 3 monitoring stages were continuous. 
In terms of AGB (Figure $8 \mathrm{a}-\mathrm{c}$ ), $\mathrm{T}_{\mathrm{HP}}$ ensured the accumulation of biomass under different early nutrient conditions, especially for $B_{0}$. The accumulation of AGB went through two periods after topdressing: a rapid growing period from booting to anthesis, and the accumulation ranged from $3.58 \sim 4.42 \mathrm{Mg} \cdot \mathrm{ha}^{-1}$ for $\mathrm{B}_{0} ; 3.79 \sim 4.46 \mathrm{Mg} \cdot \mathrm{ha}^{-1}$ for $\mathrm{B}_{1}$ and 4.44 5.13 Mg.ha ${ }^{-1}$ for $B_{2}$; and a slow accumulation period from anthesis to milk ripening with an accumulation ranged from $1.72 \sim 2.83 \mathrm{Mg} \cdot \mathrm{ha}^{-1}$ for $\mathrm{B}_{0} ; 2.41 \sim 3.56 \mathrm{Mg} \cdot \mathrm{ha}^{-1}$ for $B_{1}$ and $2.46 \sim 2.75 \mathrm{Mg} \cdot \mathrm{ha}^{-1}$ for $B_{2}$. With the growth of winter wheat, the differences in AGBs between different topdressing methods gradually increased, so we focused on the AGBs at milk ripening stage. It was found that under the $\mathrm{B}_{0}$ condition, $\mathrm{T}_{\mathrm{HP}}$ achieved an average AGB of $12.55 \mathrm{Mg} \cdot \mathrm{ha}^{-1}$, which was close to $\mathrm{T}_{\mathrm{LF}}\left(12.59 \mathrm{Mg} \cdot \mathrm{ha}^{-1}\right)$ and significantly higher than $\mathrm{T}_{\mathrm{RL}}\left(11.55 \mathrm{Mg} \cdot \mathrm{ha}^{-1}\right)$ and $\mathrm{T}_{\mathrm{LZ}}\left(12.31 \mathrm{Mg} \cdot \mathrm{ha}^{-1}\right)$. Under $\mathrm{B}_{1}$ and $\mathrm{B}_{2}$ conditions, the average AGBs of $T_{H P}, T_{L F}, T_{R L}$, and $T_{L Z}$ were not significantly different but were significantly higher than that of $\mathrm{T}_{0}$.

(B)

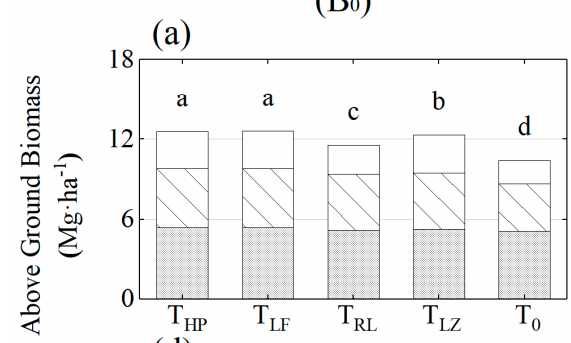

(d)
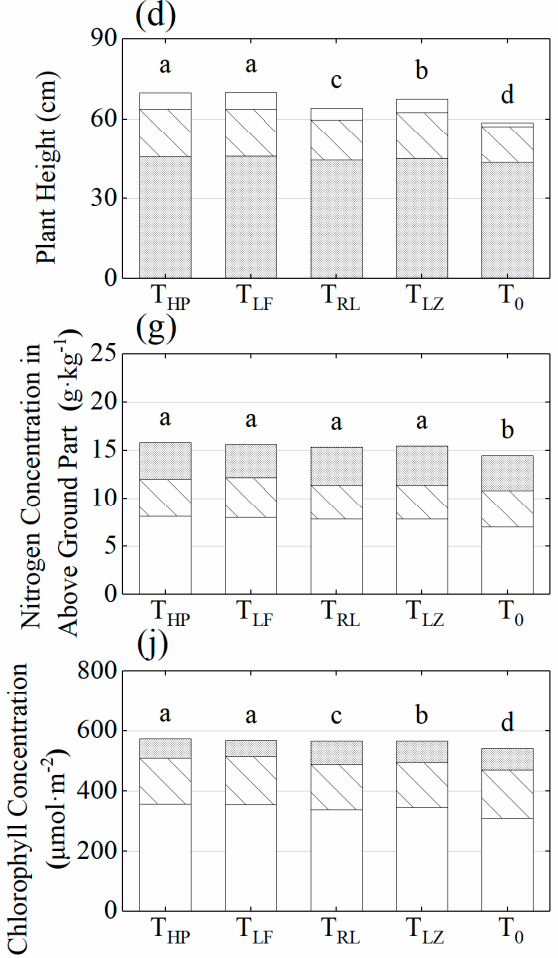

Milk Ripe $\square$ Anthesis $\square$ Booting

$\left(\mathrm{B}_{1}\right)$
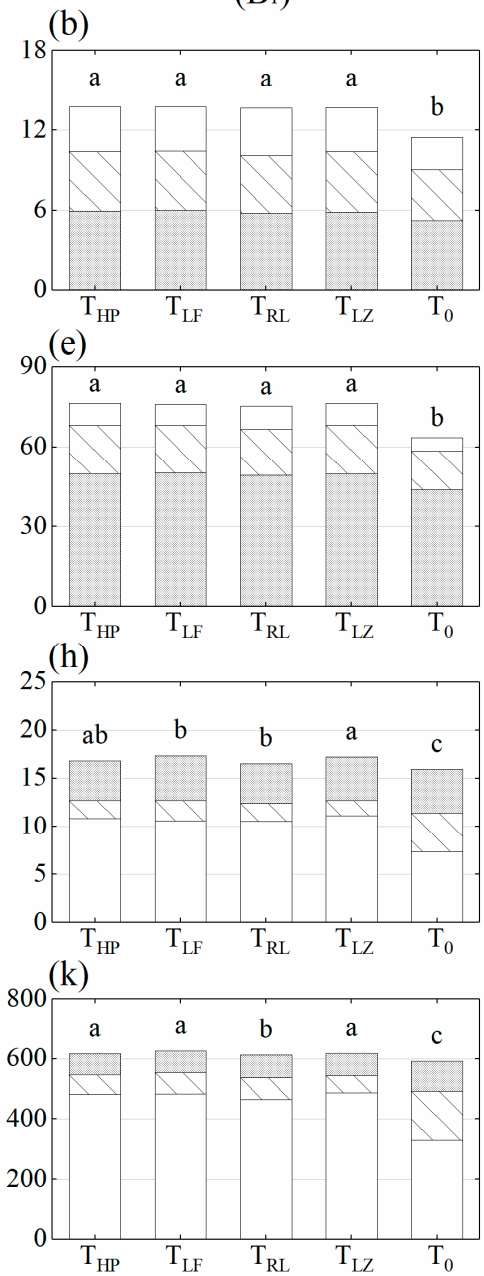

$\left(\mathrm{B}_{2}\right)$
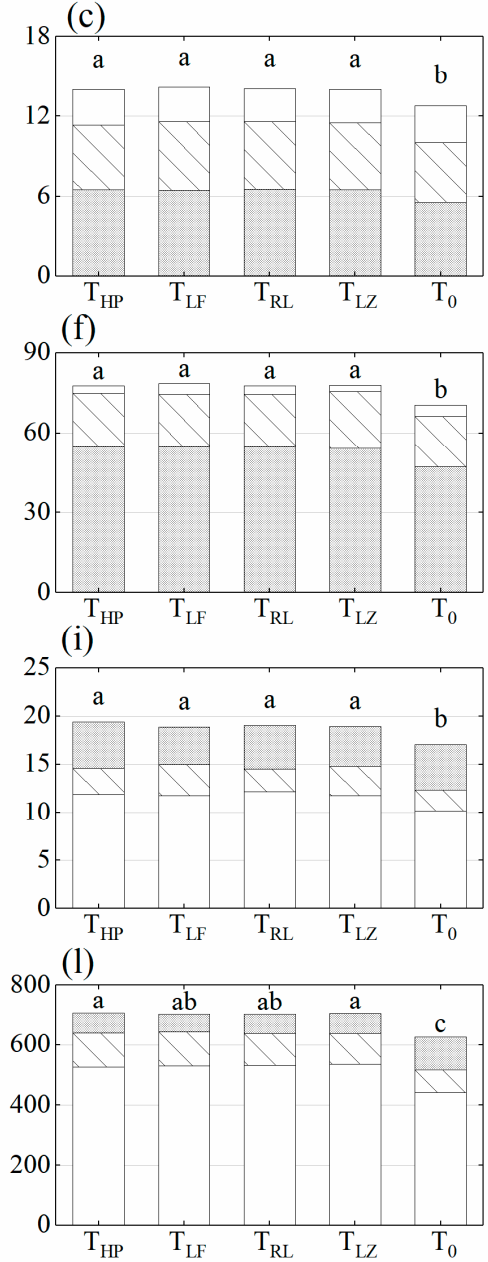

Figure 8. Growing status of winter wheat after topdressing. (a-c) Cumulative graphs of above ground biomass. (d-f) Cumulative graphs of plant height. (g-i) Decreasing graphs of nitrogen concentration in above ground part. ( $\mathbf{j}-\mathbf{1})$ Decreasing graphs of chlorophyll concentration. $\left(\mathrm{B}_{0}, \mathrm{~B}_{1}\right.$ and $\mathrm{B}_{2}$ represent basal fertilizer levels of 0,57 and $114 \mathrm{~kg} \cdot \mathrm{N} \cdot \mathrm{ha}{ }^{-1}$, respectively; $\mathrm{T}_{\mathrm{HP}}, \mathrm{T}_{\mathrm{LF}}$, $\mathrm{T}_{\mathrm{RL}}, \mathrm{T}_{\mathrm{LZ}}$, and $\mathrm{T}_{0}$ represent different topdressing methods; different letters indicate significance using Fischer's protected least significant difference at $p<0.05$ at the milk ripe stage). 
The increase in plant height (Figure $8 \mathrm{~d}-\mathrm{f}$ ) was similar to that of AGB, and the slowdown in growth from anthesis to milk ripening was more obvious. As for the $\mathrm{B}_{2}$ condition, the increment of height for each topdressing methods in this stage only reached $2.40 \sim 4.00 \mathrm{~cm}$. We focused on the plant height of each topdressing method at the milk ripening stage for the same reason as for AGB. Under the $\mathrm{B}_{0}$ condition, $\mathrm{T}_{\mathrm{HP}}$ achieved an average plant height of $69.94 \mathrm{~cm}$, which was close to that of $\mathrm{T}_{\mathrm{LF}}(70.08 \mathrm{~cm})$ and significantly higher than those of $T_{R L}(64.09 \mathrm{~cm})$ and $T_{L Z}(67.50 \mathrm{~cm})$. Under $B_{1}$ and $B_{2}$ conditions, the average AGBs of $T_{H P}, T_{L F}, T_{R L}$, and $T_{L Z}$ were not significantly different but were significantly higher than that of $\mathrm{T}_{0}$.

The NCA of winter wheat (Figure $8 \mathrm{~g}-\mathrm{i}$ ) continued to decrease throughout the growth periods. $\mathrm{T}_{\mathrm{HP}}$ slowed the decreasing trend compared to other topdressing methods, but there was no significant difference between $T_{H P}, T_{L F}, T_{R L}$ and $T_{L Z}$ at the milk ripe stage. The mean NCA of $\mathrm{T}_{\mathrm{HP}}$ at the milk ripe stage was $8.14,10.80$ and $11.87 \mathrm{~g} . \mathrm{kg}^{-1}$ under $\mathrm{B}_{0}, \mathrm{~B}_{1}$ and $\mathrm{B}_{2}$ conditions, respectively.

The chlorophyll concentration (Figure $8 \mathbf{j}-1$ ) increased for a transitory period after topdressing and decreased from the booting to milk ripe stages in all treatments. $\mathrm{T}_{\mathrm{HP}}$ slowed the reduction in chlorophyll concentration and maintained the chlorophyll concentration at $357.11 \mu \mathrm{mol} \cdot \mathrm{m}^{-2}, 481.45 \mu \mathrm{mol} \cdot \mathrm{m}^{-2}$ and $526.36 \mu \mathrm{mol} \cdot \mathrm{m}^{-2}$ for $\mathrm{B}_{0}, \mathrm{~B}_{1}$, and $\mathrm{B}_{2}$, respectively, at the milk ripe stage.

Overall, $\mathrm{T}_{\mathrm{HP}}$ performed well in terms of winter wheat development among all topdressing methods in multiple growing stages regardless of the nutritional conditions during the early stages.

\subsection{Harvest Index and Nitrogen Use Efficiency}

In terms of the grain yield (Figure $9 \mathrm{a}-\mathrm{c}$ ), $\mathrm{T}_{\mathrm{HP}}$ achieved high yield under different basal fertilizer levels. The average grain yields of $\mathrm{T}_{\mathrm{HP}}$ were $5.41,6.17$ and $6.58 \mathrm{Mg} \cdot \mathrm{ha}^{-1}$ under $B_{0}, B_{1}$ and $B_{2}$ level, respectively. The grain yields of $T_{H P}$ were not significantly different from those of $\mathrm{T}_{\mathrm{LF}}\left(\mathrm{B}_{0}: 5.42 \mathrm{Mg} \cdot \mathrm{ha}^{-1}, \mathrm{~B}_{1}: 6.23 \mathrm{Mg} \cdot \mathrm{ha}^{-1}, \mathrm{~B}_{2}: 6.59 \mathrm{Mg} \cdot \mathrm{ha}^{-1}\right)$, and $\mathrm{T}_{\mathrm{LZ}}\left(\mathrm{B}_{0}\right.$ : $5.29 \mathrm{Mg} \cdot \mathrm{ha}^{-1}, \mathrm{~B}_{1}: 6.16 \mathrm{Mg} \cdot \mathrm{ha}^{-1}, \mathrm{~B}_{2}: 6.59 \mathrm{Mg} \cdot \mathrm{ha}^{-1}$ ) under all three basal fertilizer levels but were significantly higher than that of $\mathrm{T}_{\mathrm{RL}}$ when the early-stage nutrition was insufficient $\left(\mathrm{B}_{0}: 5.17 \mathrm{Mg} \cdot \mathrm{ha}^{-1}\right.$ and $\left.\mathrm{B}_{1}: 5.93 \mathrm{Mg} \cdot \mathrm{ha}^{-1}\right)$.

The difference in straw biomass (Figure $9 d-f$ ) was not significant among $T_{H P}, T_{L F}, T_{R L}$, and $\mathrm{T}_{\mathrm{LZ}}$. Only when nitrogen deficiency occurred in the early stage $\left(\mathrm{B}_{0}\right)$ did the average straw biomass of $\mathrm{T}_{\mathrm{HP}}\left(7.77 \mathrm{Mg} \cdot \mathrm{ha}^{-1}\right)$ was slightly higher than that of $\mathrm{T}_{\mathrm{LF}}\left(0.77 \mathrm{Mg} \cdot \mathrm{ha}^{-1}\right)$, $\mathrm{T}_{\mathrm{RL}}\left(0.73 \mathrm{Mg} \cdot \mathrm{ha}^{-1}\right)$ and $\mathrm{T}_{\mathrm{LZ}}\left(0.75 \mathrm{Mg} \cdot \mathrm{ha}^{-1}\right)$.

Overall, $\mathrm{T}_{\mathrm{HP}}$ presented high $\mathrm{PFP}_{\mathrm{t}} \mathrm{s}$ under different basal fertilizer levels (Table 3). Under the $\mathrm{B}_{0}$ and $\mathrm{B}_{1}$ levels, the $\mathrm{PFP}_{\mathrm{t}}$ of $\mathrm{T}_{\mathrm{HP}}$ was higher than that of $\mathrm{T}_{\mathrm{RL}}$ and $\mathrm{T}_{\mathrm{LZ}}$, and under the $B_{2}$ level, it was higher than that of $T_{L F}$ and $T_{R L}$. However, the difference between each topdressing method was not significant.

Table 3. Partial factor productivity from applied nitrogen of topdressing $\left(\mathrm{PFP}_{\mathrm{t}}\right)$.

\begin{tabular}{cccc}
\hline PFP $_{\mathbf{t}}$ & $\mathbf{B}_{\mathbf{0}}$ & $\mathbf{B}_{\mathbf{1}}$ & $\mathbf{B}_{\mathbf{2}}$ \\
\hline $\mathrm{T}_{\mathrm{HP}}$ & $11.86 \pm 1.69(\mathrm{a})$ & $14.90 \pm 2.12(\mathrm{a})$ & $9.84 \pm 1.65(\mathrm{a})$ \\
$\mathrm{T}_{\mathrm{LF}}$ & $12.01 \pm 1.63(\mathrm{a})$ & $14.72 \pm 2.03(\mathrm{a})$ & $9.56 \pm 1.72(\mathrm{a})$ \\
$\mathrm{T}_{\mathrm{RL}}$ & $10.92 \pm 2.56(\mathrm{a})$ & $12.56 \pm 1.74(\mathrm{a})$ & $9.37 \pm 1.39(\mathrm{a})$ \\
$\mathrm{T}_{\mathrm{LZ}}$ & $11.59 \pm 1.85(\mathrm{a})$ & $14.72 \pm 1.80(\mathrm{a})$ & $10.12 \pm 1.87(\mathrm{a})$ \\
\hline
\end{tabular}

$\mathrm{B}_{0}, \mathrm{~B}_{1}$ and $\mathrm{B}_{2}$ represent basal fertilizer levels of 0,57 , and $114 \mathrm{~kg} \cdot \mathrm{N} \cdot \mathrm{ha}{ }^{-1}$, respectively. $\mathrm{T}_{\mathrm{HP}}, \mathrm{T}_{\mathrm{LF}}, \mathrm{T}_{\mathrm{RL}}$, and $\mathrm{T}_{\mathrm{LZ}}$ represent different topdressing methods. Different letters indicate significance within the same column using Fischer's protected least significant difference at $p<0.05$. 
(a)

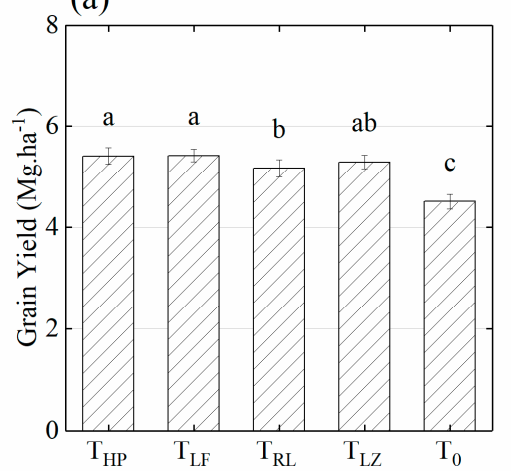

(d)

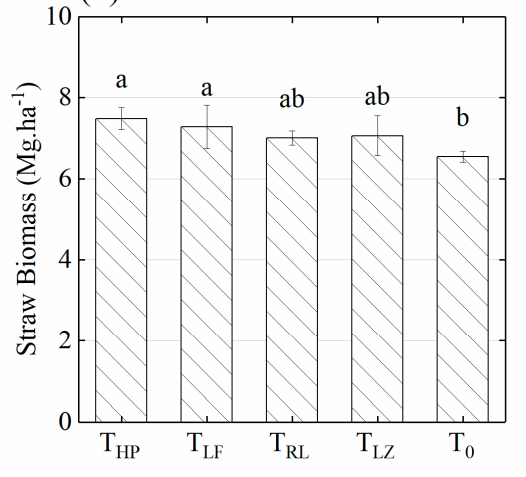

$\left(\mathrm{B}_{1}\right)$

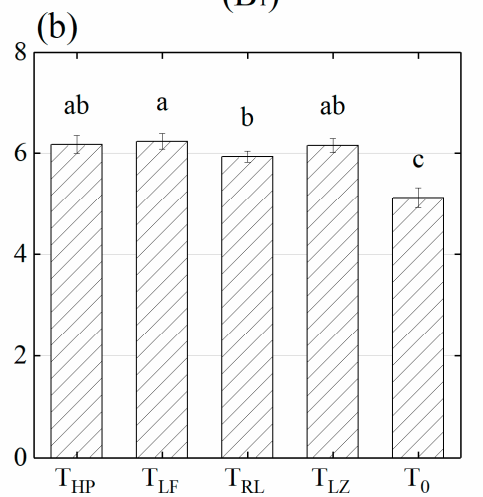

(e)

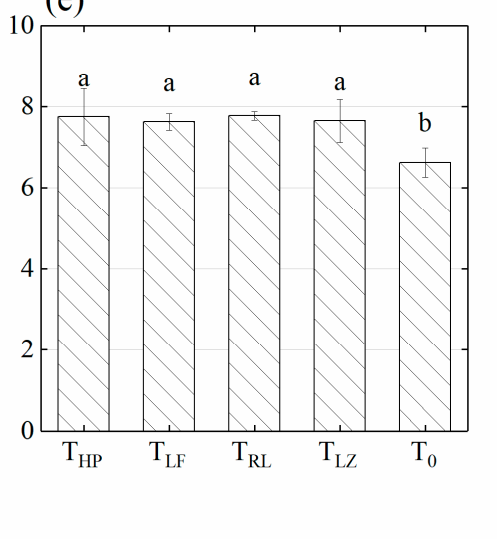

$\left(\mathrm{B}_{2}\right)$

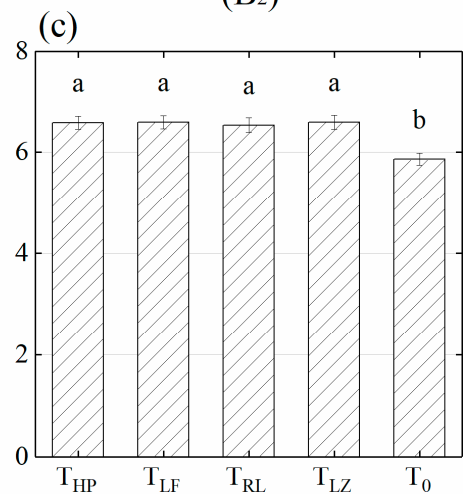

(f)

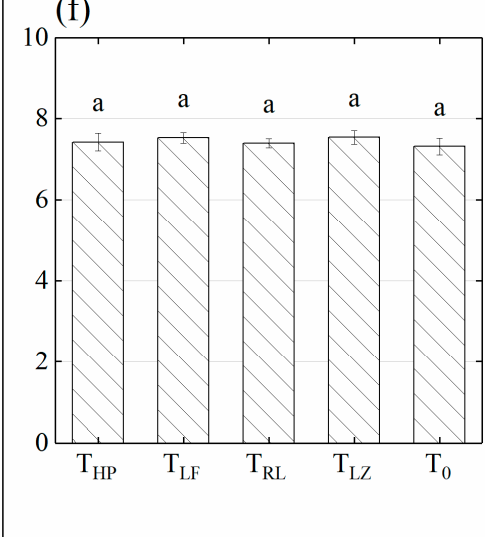

Figure 9. Grain yield and straw biomass of winter wheat under different topdressing methods. (a-c) Grain yields of different topdressing methods under three basal fertilizer levels. (d-f) Straw biomasses of different topdressing methods under three basal fertilizer levels. $\left(B_{0}, B_{1}\right.$, and $B_{2}$ represent basal fertilizer levels of 0,57 and $114 \mathrm{~kg} \cdot N \cdot h{ }^{-1}$, respe $\left(B_{0}, B_{1}\right.$, and $B_{2}$ represent basal fertilizer levels of 0,57 and $114 \mathrm{~kg} \cdot \mathrm{N} \cdot \mathrm{ha}^{-1}$, respectively; $\mathrm{T}_{\mathrm{HP}}, \mathrm{T}_{\mathrm{LF}}, \mathrm{T}_{\mathrm{RL}}, \mathrm{T}_{\mathrm{PGY}}$, and $\mathrm{T}_{\mathrm{LZ}}$ represent different topdressing methods; different letters indicate significance using Fischer's protected least significant difference at $p<0.05)$.

\section{Discussion}

\subsection{Difference in NFT}

As shown in Section 3.2, the variable topdressing methods $\left(\mathrm{T}_{\mathrm{HP}}, \mathrm{T}_{\mathrm{RL}}\right.$ and $\left.\mathrm{T}_{\mathrm{LZ}}\right)$ tested in this experiment varied in NFT for winter wheat under the three preceding nutritional conditions, as the predictions of growth potential were different. Under $\mathrm{B}_{2}$ conditions, $\mathrm{T}_{\mathrm{HP}}$, $\mathrm{T}_{\mathrm{RL}}$, and $\mathrm{T}_{\mathrm{LZ}}$ recommended similar NFTs, which were lower than that of $\mathrm{T}_{\mathrm{LF}}$ because the basal fertilizer was excessive and the additional fertilizer for topdressing had no contribution to yield. With the decrease in basal fertilizer, $T_{R L}$ and $T_{L Z}$ gradually reduced NFTs for $B_{1}$ and $B_{0}$ due to the diminishing expectation of production, while the circumstance was inverse for $\mathrm{T}_{\mathrm{HP}}$, as it increased NFT for $\mathrm{B}_{1}$ and $\mathrm{B}_{0}$ aiming to compensate for the deficiency of nitrogen.

\subsection{Differences in Responses of Winter Wheat to NFT Recommended by Each Topdressing Method}

The difference in topdressing methods had a significant influence on the growth and yield formation of winter wheat, especially when the basal fertilizer was deficient, which was consistent with the research conducted by Xu et al. in 2018 [31]. The NCA kept decreasing throughout the monitoring periods, and the process was more rapid for winter wheat with nitrogen deficiency in the early stage $\left(B_{0}\right)$ [24]. Topdressing could slow down the decreasing process of NCA, and the NCAs of $\mathrm{T}_{0}$ were therefore significantly lower than those of other topdressing methods. It was supposed that the NCAs of winter wheat with low NFTs should decrease faster than those with high NFTs. The fact, however, is that 
no significant difference was found in NCA between the different topdressing methods. This is because well-nourished wheat tended to achieve higher AGBs, and according to the N dilution theory, the NCA decreases with the accumulation of AGB. Due to the influence of many factors, the variation of NCAs with NFT did not show obvious regularity, and as a result, the NCA at the milk ripe stage of $\mathrm{T}_{\mathrm{HP}}$ was not different from that of $\mathrm{T}_{\mathrm{RL}}$, even though $15.35 \mathrm{~kg} \cdot \mathrm{N} \cdot \mathrm{ha}^{-1}$ additional NFT was applied under the $\mathrm{B}_{0}$ condition. However, the additional NFT retarded the breakdown of chlorophyll, so the chlorophyll concentrations of $\mathrm{T}_{\mathrm{HP}}$ and $\mathrm{T}_{\mathrm{LF}}$ were significantly higher than those of $\mathrm{T}_{\mathrm{RL}}$ and $\mathrm{T}_{\mathrm{LZ}}$. This support the photosynthesis and material accumulation of winter wheat and presented a significant difference in AGB and plant height at the milk ripe stage. The additional material accumulation is transferred to the grain at late growing stages and manifested as grain yield differences. Under the $B_{1}$ basal fertilizer level, the AGB and plant height were not different among the four topdressing methods, while the N, chlorophyll concentration, and grain yield of $\mathrm{T}_{\mathrm{RL}}$ were significantly lower than those of the other topdressing methods, implying that the $\mathrm{N}$ and chlorophyll concentrations are more sensitive to the nutrient status. Under the $B_{2}$ basal fertilizer level, all tested growth parameters and the grain yield were not significantly different among the 4 topdressing methods, demonstrating that excessive NFT is unable to increase production.

\subsection{Limitations of the Study}

Determining the growth potential of winter wheat requires exhaustive work, as the accumulation in AGB changes with the monitoring time. However, we only conducted this experiment for one growing season; thus, the impacts of interannual meteorological variabilities and planting time were not analyzed in the method based on improved growth estimation. Multi-season topdressing experiments are needed to improve the adaptability of $\mathrm{T}_{\mathrm{HP}}$ to different topdressing times. In addition, this work is based on one cultivar and conducted at one experimental site, and as such, large-area applications and evaluation under diverse farm-field conditions are needed to improve this preliminary method.

In this study, we used RV to estimate the AGB of winter wheat at topdressing. However, the process is inefficient, as the calculation of RV requires manually measured plant height. With the development of image processing methods, it is convenient to accurately predict crop biomass with UAV-based remote sensing alone [17,32,33]. Therefore, further research is needed to deeply mine data obtained by UAV-based remote sensing to simplify topdressing.

\section{Conclusions}

To optimize winter wheat topdressing in monitoring efficiency and fertilizer use efficiency, we constructed a topdressing method based on determing biomass increments with UAV-based remote sensing $\left(\mathrm{T}_{\mathrm{HP}}\right)$ and compared the effect of this method with other topdressing methods in a field experiment. The results showed that $\mathrm{T}_{\mathrm{HP}}$ has the potential to ensure grain yield and avoid excessive $\mathrm{N}$ fertilization. $\mathrm{T}_{\mathrm{HP}}$ reduced the nitrogen application amount of topdressing by $4.18 \sim 4.61 \%$ over $\mathrm{T}_{\mathrm{LF}}$, with no significant decrease in grain yield, when the early-stage nutrition condition was sufficient, and maintained a relatively high grain yield of $5.41 \mathrm{Mg} \cdot \mathrm{ha}^{-1}$, which was $17.83 \%$ and $20.68 \%$ higher than that of $\mathrm{T}_{\mathrm{LZ}}$ and $\mathrm{T}_{\mathrm{RL}}$ when the early-stage nutrition condition was deficient, as it was recommended to increase the nitrogen application amount of topdressing when nitrogen deficiency occurred, and moderately reduce the topdressing amount when the nitrogen levels were sufficient. The adaptation of early-stage nutrition conditions was achieved by adjusting the NFT based on estimation of the maximum growth potential. More studies are necessary to further improve this topdressing method for a wider range of applications and obtain information acquired by UAV-based remote sensing. 
Author Contributions: X.L. conceived the method. J.J. and Y.N. conducted the experiment. J.J. analyzed the results and wrote the original version. X.L., J.L. and J.C. edited the text. K.X., Y.J., R.J. and C.W. provided suggestions. All authors have read and agreed to the published version of the manuscript.

Funding: This work was supported in part by the National Natural Science Foundation of China under Grant No. 41877021 and 41171265.

Institutional Review Board Statement: Not applicable.

Informed Consent Statement: Not applicable.

Data Availability Statement: Data sharing is not applicable to this article.

Acknowledgments: This work was supported by the National Natural Science Foundation of China (Grant No. 41877021 and 41171265). The authors would like to acknowledge Raun and Lukina for their previous contributions, presented in publication $[20,21]$.

Conflicts of Interest: The authors declare no conflict of interest.

\section{References}

1. Ren, S.; Guo, B.; Wu, X.; Zhang, L.; Ji, M.; Wang, J. Winter wheat planted area monitoring and yield modeling using MODIS data in the Huang-Huai-Hai Plain, China. Comput. Electron. Agric. 2021, 182, 106049. [CrossRef]

2. Liu, B.-Y.; Zhao, X.; Li, S.-S.; Zhang, X.-Z.; Virk, A.L.; Qi, J.-Y.; Kan, Z.-R.; Wang, X.; Ma, S.-T.; Zhang, H.-L. Meta-analysis of management-induced changes in nitrogen use efficiency of winter wheat in the North China Plain. J. Clean. Prod. 2020, 251, 119632. [CrossRef]

3. Xue, L.; Yang, L. Recommendations for nitrogen fertiliser topdressing rates in rice using canopy reflectance spectra. Biosyst. Eng. 2008, 100, 524-534. [CrossRef]

4. Balasubramanian, V.; Morales, A.; Cruz, R.; Abdulrachman, S. On-farm adaptation of knowledge-intensive nitrogen management technologies for rice systems. Nutr. Cycl. Agroecosyst. 1998, 53, 59-69. [CrossRef]

5. Liu, S.; Li, L.; Fan, H.; Guo, X.; Wang, S.; Lu, J. Real-time and multi-stage recommendations for nitrogen fertilizer topdressing rates in winter oilseed rape based on canopy hyperspectral data. Ind. Crop. Prod. 2020, 154, 112699. [CrossRef]

6. Qiang, S.-C.; Zhang, F.-C.; Dyck, M.; Zhang, Y.; Xiang, Y.-Z.; Fan, J.-L. Determination of critical nitrogen dilution curve based on leaf area index for winter wheat in the Guanzhong Plain, Northwest China. J. Integr. Agric. 2019, 18, 2369-2380. [CrossRef]

7. Torino, M.S.; Ortiz, B.V.; Fulton, J.P.; Balkcom, K.S.; Wood, C.W. Evaluation of Vegetation Indices for Early Assessment of Corn Status and Yield Potential in the Southeastern United States. Agron. J. 2014, 106, 1389-1401. [CrossRef]

8. Zhao, G.; Miao, Y.; Wang, H.; Su, M.; Fan, M.; Zhang, F.; Jiang, R.; Zhang, Z.; Liu, C.; Liu, P.; et al. A preliminary precision rice management system for increasing both grain yield and nitrogen use efficiency. Field Crop. Res. 2013, 154, 23-30. [CrossRef]

9. Wood, G.A.; Welsh, J.P.; Godwin, R.J.; Taylor, J.C.; Earl, R.; Knight, S.M. Real-time Measures of Canopy Size as a Basis for Spatially Varying Nitrogen Applications to Winter Wheat sown at Different Seed Rates. Biosyst. Eng. 2003, 84, 513-531. [CrossRef]

10. Tao, M.; Ma, X.; Huang, X.; Liu, C.; Deng, R.; Liang, K.; Qi, L. Smartphone-based detection of leaf color levels in rice plants. Comput. Electron. Agric. 2020, 173, 105431. [CrossRef]

11. Raj, R.; Kar, S.; Nandan, R.; Jagarlapudi, A. Precision Agriculture and Unmanned Aerial Vehicles (UAVs). In Unmanned Aerial Vehicle: Applications in Agriculture and Environment; Springer Science and Business Media LLC: Cham, Switzerland, 2019; pp. 7-23.

12. Tsouros, D.C.; Bibi, S.; Sarigiannidis, P.G. A review on UAV-based applications for precision agriculture. Information 2019, 10, 349. [CrossRef]

13. Matsumura, K. Unmanned Aerial Vehicle (UAV) for Fertilizer Management in Grassland of Hokkaido, Japan. In Unmanned Aerial Vehicle: Applications in Agriculture and Environment; Springer International Publishing: Cham, Switzerland, 2020; pp. 39-50.

14. Zhang, M.; Zhou, J.; Sudduth, K.A.; Kitchen, N.R. Estimation of maize yield and effects of variable-rate nitrogen application using UAV-based RGB imagery. Biosyst. Eng. 2020, 189, 24-35. [CrossRef]

15. Malambo, L.; Popescu, S.; Murray, S.; Putman, E.; Pugh, N.; Horne, D.; Richardson, G.; Sheridan, R.; Rooney, W.; Avant, R.; et al. Multitemporal field-based plant height estimation using 3D point clouds generated from small unmanned aerial systems high-resolution imagery. Int. J. Appl. Earth Obs. Geoinf. 2018, 64, 31-42. [CrossRef]

16. Bendig, J.; Yu, K.; Aasen, H.; Bolten, A.; Bennertz, S.; Broscheit, J.; Gnyp, M.L.; Bareth, G. Combining UAV-based plant height from crop surface models, visible, and near infrared vegetation indices for biomass monitoring in barley. Int. J. Appl. Earth Obs. Geoinf. 2015, 39, 79-87. [CrossRef]

17. Furukawa, F.; Maruyama, K.; Saito, Y.K.; Kaneko, M. Corn Height Estimation Using UAV for Yield Prediction and Crop Monitoring. In Unmanned Aerial Vehicle: Applications in Agriculture and Environment; Springer Science and Business Media LLC: Cham, Switzerland, 2019; pp. 51-69.

18. Xiong, D.; Chen, J.; Yu, T.; Gao, W.; Ling, X.; Li, Y.; Peng, S.; Huang, J. SPAD-based leaf nitrogen estimation is impacted by environmental factors and crop leaf characteristics. Sci. Rep. 2015, 5, 13389. [CrossRef] 
19. Thind, H.S.; Gupta, R.K. Need based nitrogen management using the chlorophyll meter and leaf colour chart in rice and wheat in South Asia: A review. Nutr. Cycl. Agroecosyst. 2010, 88, 361-380.

20. Raun, W.; Solie, G.J.; Johnson, M.; Stone, R.; Mullen, K.; Freeman, W.; Thomason, E. Lukina, Improving Nitrogen Use Efficiency in Cereal Grain Production with Optical Sensing and Variable Rate Application. Agron. J. 2002, 94, 815-820. [CrossRef]

21. Raun, W.R.; Solie, J.B.; Johnson, G.V.; Stone, M.L.; Lukina, E.V.; Thomason, W.E.; Schepers, J.S. In-Season Prediction of Potential Grain Yield in Winter Wheat Using Canopy Reflectance. Agron. J. 2001, 93, 131-138. [CrossRef]

22. Xue, L.; Li, G.; Qin, X.; Yang, L.; Zhang, H. Topdressing nitrogen recommendation for early rice with an active sensor in south China. Precis. Agric. 2013, 15, 95-110. [CrossRef]

23. Chemists, A.; Horwitz, W. Official Methods of Analysis; Association of Official Agricultural Chemists: Rockville, MD, USA, 1984.

24. Zhao, B.; Niu, X.; Ata-Ul-Karim, S.T.; Wang, L.; Duan, A.; Liu, Z.; Lemaire, G. Determination of the post-anthesis nitrogen status using ear critical nitrogen dilution curve and its implications for nitrogen management in maize and wheat. Eur. J. Agron. 2020, 113, 125967. [CrossRef]

25. Tunca, E.; Köksal, E.S.; Çetin, S.; Ekiz, N.M.; Balde, H. Yield and leaf area index estimations for sunflower plants using unmanned aerial vehicle images. Environ. Monit. Assess. 2018, 190, 682. [CrossRef]

26. Zhou, Q.; Robson, M. Automated rangeland vegetation cover and density estimation using ground digital images and a spectral-contextual classifier. Int. J. Remote Sens. 2001, 22, 3457-3470. [CrossRef]

27. Richardson, M.D.; Karcher, D.E.; Purcell, L.C. Quantifying Turfgrass Cover Using Digital Image Analysis. Crop. Sci. 2001, 41, 1884-1888. [CrossRef]

28. Li, B.; Liu, R.; Liu, S.; Liu, Q.; Liu, F.; Zhou, G. Monitoring vegetation coverage variation of winter wheat by low-altitude UAV remote sensing system. Trans. Chin. Soc. Agric. Eng. 2012, 28, 160-165.

29. Lencina, A.; Weber, C. Maximum discrimination index: A tool for land cover identification. Int. J. Environ. Sci. Technol. 2019, 17, 1113-1122. [CrossRef]

30. Cassman, K.; Ladha, W.; Reichardt, D. Singh, Opportunities for increased nitrogen-use efficiency from improved resource management in irrigated rice systems. Field Crop. Res. 1998, 56, 7-39. [CrossRef]

31. Xu, H.-C.; Dai, X.-L.; Chu, J.-P.; Wang, Y.-C.; Yin, L.-J.; Ma, X.; Dong, S.; He, M.-R. Integrated management strategy for improving the grain yield and nitrogen-use efficiency of winter wheat. J. Integr. Agric. 2018, 17, 315-327. [CrossRef]

32. Cen, H.; Wan, L.; Zhu, J.; Li, Y.; Li, X.; Zhu, Y.; Weng, H.; Wu, W.; Yin, W.; Xu, C.; et al. Dynamic monitoring of biomass of rice under different nitrogen treatments using a lightweight UAV with dual image-frame snapshot cameras. Plant Methods 2019, 15, 32. [CrossRef] [PubMed]

33. Zheng, H.; Cheng, T.; Zhou, M.; Li, D.; Yao, X.; Tian, Y.; Cao, W.; Zhu, Y. Improved estimation of rice aboveground biomass combining textural and spectral analysis of UAV imagery. Precis. Agric. 2019, 20, 611-629. [CrossRef] 